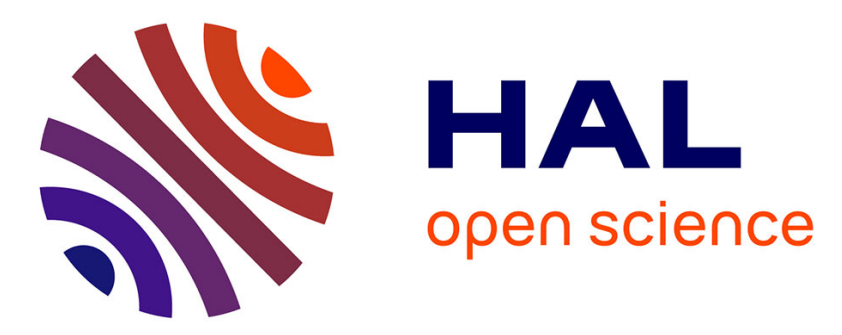

\title{
Experimental design approach for identification of the factors influencing the $\gamma$-radiolysis of ion exchange resins
}

C Rébufa, A Traboulsi, V Labed, Nathalie Dupuy, M Sergent

\section{To cite this version:}

C Rébufa, A Traboulsi, V Labed, Nathalie Dupuy, M Sergent. Experimental design approach for identification of the factors influencing the $\gamma$-radiolysis of ion exchange resins. Radiation Physics and Chemistry, 2015, 106, pp.223-234. 10.1016/j.radphyschem.2014.07.020 . hal-01451454

\author{
HAL Id: hal-01451454 \\ https://hal.science/hal-01451454
}

Submitted on 12 Apr 2018

HAL is a multi-disciplinary open access archive for the deposit and dissemination of scientific research documents, whether they are published or not. The documents may come from teaching and research institutions in France or abroad, or from public or private research centers.
L'archive ouverte pluridisciplinaire HAL, est destinée au dépôt et à la diffusion de documents scientifiques de niveau recherche, publiés ou non, émanant des établissements d'enseignement et de recherche français ou étrangers, des laboratoires publics ou privés. 


\title{
Experimental design approach for identification of the factors influencing the $\gamma$-radiolysis of ion exchange resins
}

\author{
C. Rébufa ${ }^{a, *}$, A. Traboulsi ${ }^{\mathrm{a}, \mathrm{c}}$, V. Labed $^{\mathrm{b}}$, N. Dupuy ${ }^{\mathrm{a}}$, M. Sergent $^{\mathrm{a}}$ \\ a Aix-Marseille Université, LISA EA 4672-METICA, 13397 Marseille Cedex 20, France \\ ${ }^{\mathrm{b}}$ CEA Marcoule, DEN/DTCD/SPDE/SPDE, BP 17 171, 30207 Bagnols-sur-Cèze, France \\ ' Subatech, UMR 6457, Laboratoire de physique subatomique et des technologies associées, 4 Rue Alfred Kastler, La Chantrerie, BP 20722, \\ 44307 Nantes Cedex 3, France
}

\section{H I G H L I G H T S}

- Ion exchange resins were irradiated under different conditions.

- Resins degradation was studied from the gases and water-soluble products analyses.

- A screening design allowed identifying the factors influencing gases production.

- The resins gamma stability was estimated from the response of experimental designs.

- A reaction scheme was proposed for each resin degraded under different conditions.
G R A P H I C A L A B S T R A C T

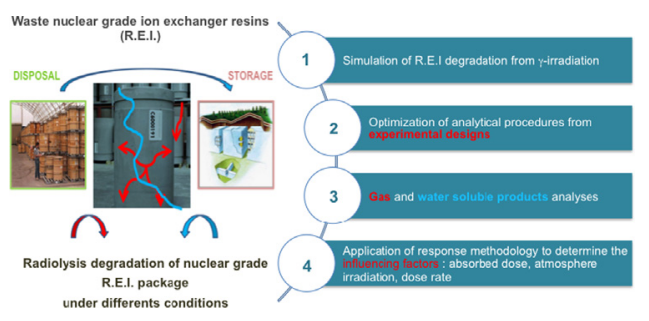

Keywords:

Ion exchange resin

Gamma irradiation

Gas analysis

Experimental design

\section{A B S T R A C T}

Gamma radiolysis was investigated on a nuclear grade mixed bed ion exchange resin and its pure components under different irradiation conditions. Screening designs were performed to identify the factors influencing gas production after their $\gamma$-radiolysis and to compare their $\gamma$-degradation stability. Only hydrogen and trimethylamine quantities were considered as the response in the experimental designs. The other detected gases and water-soluble products were used to improve the resins degradation. Aerobic irradiation atmosphere decreased the $\mathrm{H}_{2 \mathrm{~g}}$ production of $\mathrm{AmbOH}, \mathrm{MB} 400$, and amines. The water presence increased the $\mathrm{H}_{2 \mathrm{~g}}$ quantities for $\mathrm{AmbH}$ and decreased those for MB400 resin. Liquid water had no effect on $\mathrm{H}_{2 \mathrm{~g}}$ production from $\mathrm{AmbOH}$ but was favorable to increased amine production. The $\mathrm{H}_{2 \mathrm{~g}}$ production of $\mathrm{AmbH}$ increased with the absorbed dose that had little effect on the AmbOH resin. No impact of dose on the $\mathrm{H}_{2 \mathrm{~g}}$ production was detected for MB400 that appeared to be less degraded.

\footnotetext{
Abbreviations: AmbH, cation exchange resin; $\mathrm{AmbOH}$, anion exchange resin $\mathrm{CH}_{4 \mathrm{~g}}$, methane; $\mathrm{C}_{2} \mathrm{H}_{6 \mathrm{~g}}$, ethane; $\mathrm{CO}_{\mathrm{g}}$, carbon oxide; $\mathrm{DMA}_{\mathrm{aq}}$, dimethylamine; $\mathrm{H}_{2 \mathrm{~g}}$, hydrogen; MB400, mixed bed ion exchange resin; $\mathrm{MMA}_{\mathrm{aq}}$, monomethylamine; $\mathrm{NH}_{4 \mathrm{aq}}^{+}$, ammonium; $\mathrm{SO}_{2 \mathrm{~g}}$, sulfur dioxide; $\mathrm{SO}_{4 \mathrm{aq}}^{2-}$, sulfate ions; TMA, trimethylamine * Correspondence to: Aix-Marseille Université, LISA EA 4672-METICA, case 451avenue Normandie Niémen, 13397 Marseille Cedex 20, France. Tel.: +3349128 80 91; fax: + 33491289152 .

E-mail address: c.rebufa@univ-amu.fr (C. Rébufa).
}

\section{Introduction}

After use in the nuclear industry and during subsequent storage, ion exchange resins are exposed to ionizing radiation fields of varying intensities liable to damage their structure and producing gases and other degradation products. In this work we focused on gamma radiolysis effects on a commercial 
macroporous ion exchange resin (MB400) in a mixed bed representative of resins used in nuclear industry. To understand the behavior of its complex system under gamma-irradiation, studies were also carried out on the individual cation and anion resins constituting the MB400 sample. The pure resins were constituted by sulfonic (cation exchange resin, $\mathrm{AmbH}$ ) or trimethylammonium (anion exchange resin, AmbOH) functional groups fixed on a polystyrene-divinylbenzene backbone. The mixed bed ion exchange resin (MB400) was a mixture of the two resins: $75 \mathrm{wt} \%$ of $\mathrm{AmbH}$ and $25 \mathrm{wt} \%$ of AmbOH.

To study the impact of $\gamma$-radiolysis on these three resins, an experimental design approach was chosen to identify the influencing factors on their gas production. Several papers in the literature have shown that radiation damage of ion exchange resins could depend on the absorbed dose, the dose rate, and the irradiation atmosphere, and that the combination of these factors leads to different results according the nature of the resin, used pure or in mixed bed. Moreover, several studies (Pillay, 1986; Gangwer et al., 1977; Swyler et al., 1983a; Ichikawa and Hagiwara, 1973) reported that gamma irradiation at doses exceeding 0.1 MGy mainly altered the properties of ion exchange resins (principally the anion resins). Gamma rays led to direct radiolysis of these resins, resulting in the scission of functional groups and the formation of radical products, or to an indirect radiolytic effect through interactions, which could occur between the resin and its degradation products. Observations included darkening of the resin color, a specific odor of free amines in the case of anion resins, the release of interstitial water, weight loss, decreased exchange capacities, the production of radiolytic gases, the release of water-soluble acid and basic species, and degradation of the resin matrix accelerated in the presence of water and oxygen. The chemical composition of these materials determines the modifications that occur under radiolysis. The stability of an anion resin varies slightly with its basicity but depends on the degree of backbone cross-linking and on the ionic forms. Highly cross-linked resins were more stable and salt forms were more resistant to gamma rays than hydroxide forms (Gangwer et al., 1977; Ahmed et al., 1966; Basinski et al., 1969; Narebska et al., 1970; Baidak and LaVerne, 2010). Anion resins with primary, secondary, tertiary or quaternary amines exhibited low resistance to irradiation even at low absorbed doses. The presence of an aromatic backbone or a quaternary amine limited the $\gamma$-radiation sensitivity (Dhiman and LaVerne, 2013). The position of the quaternary ammonium group on the aromatic structure affected stability (Basinski et al., 1969; Narebska et al., 1970; Baidak and LaVerne, 2010; Hall and Streat, 1963; Litowska et al., 1974). Conversely, cation exchange resins were more stable than anion resins up to an absorbed dose of 1 MGy (Alian et al., 1984). Resins with aromatic structure or under salt forms were more gamma resistant than aliphatic ones (Swyler et al., 1983a; Nikashina et al., 1959; Dessouki et al., 1989; Mohorčič et al., 1974). The use of salt forms of resins was found to be effective in inhibiting the $\gamma$-radiation damage (Ichikawa and Hagiwara, 1973; Alian et al., 1984). The irradiation stability of $\mathrm{H}^{+}$ forms increased with the degree of cross-linking of their backbone, arbitrarily defined by the percentage of divinylbenzene used in the preparation of the resin (Ichikawa and Hagiwara, 1973). Few studies have been published concerning mixed bed ion exchange resins (Swyler et al., 1983a; Baumann, 1966; Felines et al., 1995; Cau-dit-coumes, 1999); they indicate that gamma degradation of the resin remained moderate up to an absorbed dose of $1 \mathrm{MGy}$, and increased sharply at higher values.

The nature of the atmosphere led to the formation of different products (gaseous or soluble in liquid phase) generated before or after irradiation. In the most of the ion exchange resin studies, the irradiation conditions were not described precisely. Particularly, the presence of oxygen known to be a very influential parameter involving oxidized groups accelerating polymers aging was not studied in detail during gamma radiolysis of resins. The presence of water makes the resin more radio-sensitive and the $\gamma$-radiolysis products of water exacerbate its degradation by increasing the formation of radicals. Radiolysis of the strong basic anion exchange resin in various anionic forms involved the production of gases, TMA $_{\mathrm{g}}$ and $\mathrm{H}_{2 \mathrm{~g}}$, from degradation of functional groups. The $\mathrm{H}_{2 \mathrm{~g}}$ production yield increased with the number of methyl group on the amine (Dhiman and LaVerne, 2013). The presence of varying water content in the Amberlite matrix modified its reactivity after $\gamma$-irradiation (Swyler et al., 1983a; Kiseleva et al., 1970) and the radiation-induced degradation was more significant with the $\mathrm{Cl}^{-}$ and $\mathrm{OH}^{-}$form of quaternary ammonium resin (Baidak and LaVerne, 2010). In the presence of liquid water, soluble amines such as trimethylamine $\left(\mathrm{TMA}_{\mathrm{aq}}\right)$, dimethylamine $\left(\mathrm{DMA}_{\mathrm{aq}}\right)$, monomethylamine $\left(\mathrm{MMA}_{\mathrm{aq}}\right)$ and ammonium $\left(\mathrm{NH}_{4 \mathrm{aq}}^{+}\right)$have been detected in different proportions related to the type of resin and the experimental irradiation conditions (Ahmed et al., 1966; Baidak and LaVerne, 2010; Hall and Streat, 1963). In comparison with the dry resin, the $\mathrm{H}_{2 \mathrm{~g}}$ production was increased by radiolytic decomposition of soluble amines that leach from the resin to the water and trimethylamine contributed strongly to the excess $\mathrm{H}_{2 \mathrm{~g}}$ production (Baidak and LaVerne, 2010). The off-gases from cation exchange resins were generally molecular hydrogen, carbon dioxide, sulfur dioxide, and traces of carbon monoxide (Pillay, 1986; Swyler et al., 1983a,b; Mohorčič et al., 1974). Several studies have demonstrated that air, oxygen and moisture accelerated decomposition of cation exchangers (Swyler et al., 1983a; Nikashina et al., 1959; Dessouki et al., 1989; Mohorčič et al., 1974; Semushin et al., 1950). The irradiation of cation resins generally involved the cleavage of $-\mathrm{SO}_{3} \mathrm{H}$ functional groups, the formation of free radicals and acid products. The interaction of oxygen dissolved in water with the radicals formed could cause the cross-linking and oxidation of the resin matrix with the presence of new functional groups: carboxylic acid, phenolic types, esters and sulphones (Alian et al., 1984; Mohorčič et al., 1974; Kiseleva et al., 1970; Semushin et al., 1950). In the presence of hydrated or liquid water, sulfate ions were generated (Swyler et al., 1983a; Mohorčič et al, 1974) and $\mathrm{SO}_{2 \mathrm{~g}}$ gas was not observed (Swyler et al., 1983b). Ichikawa and Hagiwara, (1973) proposed a cation exchanger degradation mechanism where the $\mathrm{SO}_{3}^{-}$radicals formed could in turn react with water molecules to form sulfate ions. Mohorčič et al. (1974) confirmed that sulfuric acid was by far the main product that was formed linearly with the water content, and $G$ $\left(\mathrm{H}_{2} \mathrm{SO}_{4}\right)$ values (sulfuric acid yield) were practically constant for samples containing $20-47$ wt\% water. Sulfuric acid has thus been reported several times as being responsible for hydrogen gas generation. The degradation of mixed bed ion exchange resins led to the release of larger amounts of interstitial water than in the case of the separate components, but a smaller release of amines and sulfate ions. These results have been explained by possible recombination between the degradation products of anion and cation resins. The mixed bed resin produced less sulfuric acid, and molecular hydrogen was the major radiolytic gas generated; its $\mathrm{H}_{2 \mathrm{~g}}$ yield was the sum of the yields of the individual components weighted by their mass percentage.

In the literature, different dose rates were used to study the $\gamma$-degradation of resins but no paper actually stated that the resin degradation reactions were governed by the dose rate. For the other materials, if the dose rate is low, oxygen diffusion is more rapid than its consumption rate, facilitating its diffusion. At high dose rates, radicals are rapidly generated but oxygen diffusion is not fast enough to compensate for its consumption.

These several works have shown that the results are difficult to compare because of the different substrates (pure resins or mixed bed), atmosphere conditions, and absorbed dose at different dose 
rates (not always specified). Few studied have been carried from the point of view of the management of waste resins. The effects of absorbed dose, the dose rate and the irradiation atmosphere have not been treated systematically. Our approach based on design strategies has several advantages over previous work: (a) experimental design allows a small number of expensive experimental runs to simulate the storage and disposal of waste nuclear resins; (b) it allowed the impact of influencing factors (absorbed dose, dose rate, irradiation atmosphere) on $\gamma$-radiolysis of the three resins to be studied in order to select the most significant one; (c) the same experimental conditions have been chosen for the three resins to compare their ability to resist $\gamma$-degradation. The levels for the "absorbed dose" factor were chosen by considering the significant reactivity of anion resin above 0.1 MGy and the stability of cation and mixed bed resins up to $1 \mathrm{MGy}$. The studied resins were submitted to $\gamma$-radiolysis at relatively high doses (from 0.1 to $4 \mathrm{MGy}$ ). To take into account the radioactive decay of the radionuclides, two levels (low or high) were chosen for the second "dose rate" factor in our experiments. To simulate the evolutionary environment in which resins were placed, three irradiation environments (aerobic, anaerobic, and anaerobic with liquid water atmosphere) were used for the last studied factor. Their degradation was followed by identification and quantification of generated gases (by mass spectrometry analysis), analysis of chemical modifications of the solid matrix (by spectroscopic techniques) and characterization of organic matter released in liquid water after irradiation by ion chromatography. The interpretation of solid analyses was not discussed here. Only the number of moles of molecular hydrogen $\left(\mathrm{H}_{2 \mathrm{~g}}\right)$ and trimethylamine (in gaseous or aqueous forms) were considered here as responses in the experimental design because they were the main components detected under the different irradiation conditions. From estimated models, effect plots were used to visualize and compare the behavior of the studied factors on the $\mathrm{H}_{2 \mathrm{~g}}$ and TMA production: irradiation environment, irradiation dose, and irradiation dose rate. The irradiation dose rate was only studied for the mixed bed resin (MB400); the pure resins were only degraded at high dose. A mathematical model was established for both pure resins and a second model for the mixed bed resin. To estimate the influence of the type of resin on the absorbed dose or the atmosphere, the responses of the three resins obtained at high dose rate have been grouped in another matrix to construct a novel mathematical model taking into account the interaction effects among these factors. Finally, based on the gas results and the presence of water-soluble products, a reaction scheme covering the formation of radiolysis products was proposed for the three resins irradiated in different environments.

\section{Materials and methods}

\subsection{Resins}

The sample used in this work were Amberlite IRA400 in hydroxide form $\left(\mathrm{AmbOH}, \mathrm{OH}^{-}\right.$form), Amberlite IR120 (AmbH, $\mathrm{H}^{+}$form $)$, and a mixed bed resin Microionex MB400 $\left(\mathrm{H}^{+} / \mathrm{OH}^{-}\right.$ form) manufactured by Rohm and Haas Company (Philadelphia $\mathrm{PA}$, USA). The AmbOH macroporous structure is formed by quaternary ammonium functional groups in hydroxide form $\left(-\mathrm{CH}_{2} \mathrm{~N}^{+}\left(\mathrm{CH}_{3}\right)_{3}, \mathrm{OH}^{-}\right)$fixed on a polystyrene backbone crosslinked with $6.0 \%$ divinylbenzene, while AmbH was substituted by $\mathrm{SO}_{3}^{-}, \mathrm{H}^{+}$groups. Microionex resin (MB400) is a commercial resin constituted by $75 \mathrm{wt} \%$ of $\mathrm{AmbH}$ and $25 \mathrm{wt} \%$ of $\mathrm{AmbOH}$. The anion and cation resins were used industrially in powder form. Supplied in bead form, the pure samples were cryoground to powder with a mean particle size of $0.8 \mu \mathrm{m}$ to obtain the same size as in the
MB400 resin. Cryogrinding was used to avoid prior heat degradation. No drying processes were applied on resins which contained initially around 53\% hydrated water.

\subsection{Gamma irradiation}

Three grams of resin were introduced in a glass tube and then conditioned under the appropriate irradiation environment. For irradiation under anaerobic conditions with liquid water, a volume of $7 \mathrm{~mL}$ of liquid water was added to cover the resin. After conditioning, the irradiation tubes were emptied of atmospheric air by vacuum aspiration, then backfilled with the appropriate gas: argon for anaerobic conditions with and without liquid water, and pure oxygen for aerobic conditions. The vacuum pressure was limited to $15-17$ mbar to maintain the sample moisture content. This operation was repeated three times to eliminate the residual air before sealing the tube at slightly below atmospheric pressure to facilitate sealing. The sealing pressure under anaerobic conditions was limited to 800 mbar whereas in presence of oxygen, it was around 1000 mbar to obtain the highest possible concentration of oxygen in order to ensure its presence throughout the irradiation period. To study the solid part of resins under aerobic conditions, irradiation tubes were not sealed to ensure the presence of oxygen during the irradiation time, which was important for the high dose at 4 MGy.

Irradiation was performed on two different irradiators both using a Cobalt-60 irradiation source to obtain two dose rates of around 0.4 or $4 \mathrm{kGy} / \mathrm{h}$ at different doses between 0.1 and $4 \mathrm{MGy}$. Dosimeters based on Perspex films (Farah et al., 2006) (routine measurements with an error of $4 \%$ and a confidence interval of 95\%) were used at the same place and in the same conditions as the samples of interest. The dose rate measured with these dosimeters was then used to calculate an average value of the dose absorbed by the studied samples.

\subsection{Mass spectrometry analysis}

Gas analysis was performed using the R30 direct-inlet quantitative gas mass spectrometer developed by the CEA Saclay (Dannoux, 2007), for chemical and isotopic analysis. Ionization occurs by electron impact; mass separation is performed with a magnetic sector and ion detection by Faraday cup and electron multiplier detectors. The mass range is from 1 to 150 atomic mass units (amu) and the detection limit is about $10 \mathrm{ppm}$ depending on the gas matrix and mass interference ( $1 \mathrm{ppm}$ for the hydrogen molecular and $10 \mathrm{ppm}$ for the other gases). The calibration of the spectrometer was realized from pure gases $\left(\mathrm{H}_{2 \mathrm{~g}}, \mathrm{He}, \mathrm{N}_{2 \mathrm{~g}}, \mathrm{CO}_{\mathrm{g}}, \mathrm{O}_{2 \mathrm{~g}}\right.$, $\mathrm{Ar}_{\mathrm{g}}$ and $\mathrm{CO}_{2 \mathrm{~g}}$ ) to determine the sensibility and the fragmentation. A part of the gas came from the irradiated glass tube was expanded in a two-liter flask under a pressure from $10^{-3}$ to 1 Torr, before to being directed to the ionization source. The formed ions were accelerated then separated in the base of the ratio mass/charge before being collected by the detector measuring ionic intensities. The identification and the quantification of the present species were made by using the following properties: (a) the uniformity of the irradiated gaseous mixture, (b) the proportionality between the ionic intensities of the molecular species and their partial pressure, (c) the additivity of the ionic intensities when several compounds gave a peak at the same mass. These properties allowed to establish a system of equations in $n$ unknowns, which were the partial pressures of the $n$ species, identified in the flask mixture and $p$ equations corresponding at the $p$ analyzed mass. For each mass, the sum of the contributions of each species with its partial pressure should be equal to the measured ionic intensity. The resolution of the system of equations described previously allowed to obtain the $n$ partial pressures 
whose the sum was equal to the total pressure measured in the flask. The composition of the species $i$ in the gas mixture was calculated from the ratio between the partial pressure of the species $i$ and the sum of the $n$ partial pressures. In order to estimate the relative errors associated with our calculated gas concentrations, all irradiations were carried out twice. The results showed that the repeatability varies between 5 and 20\% for all gases regardless of the irradiation conditions. In this investigation, we have chosen to assume an experimental repeatability of $20 \%$. This value takes into account the uncertainty on the measured absorbed dose and is acceptable considering sampling and analysis difficulties. Repetition of the irradiation experiments more than two times was not possible due to the long irradiation time needed. The results presented in this paper are the average of the two measurements. The radiolytic yield ( $G$ value) of formation or consumption of a molecular product (respectively noted $X$ or $-X)$ is given by:

$G(X)=\frac{[X] \times 9.632}{D}$

$G(X)=\frac{\left([X]-[X]_{0}\right) \times 9.632}{D}$

where $[X]_{0}$ and $[X]$ are the product concentration in mol/kg of irradiated material before irradiation and at the absorbed dose $D$ (MGy), respectively. The factor 9.632 is used to convert the chemical radiation yield from $\mathrm{mol} / \mathrm{kg} / \mathrm{MGy}$ to molecules $/ 100 \mathrm{eV}$.

\subsection{Ion chromatography analysis}

After irradiation under anaerobic conditions with liquid water, the aqueous phase was extracted by Büchner filtration, using filters with a pore size of $0.45 \mu \mathrm{m}$. A Dionex ${ }^{\circledR}$ ICS 1500 ion chromatography system was used in isocratic mode to quantitatively analyze the amines leached from resins to the supernatant solution. The system consists of a Dionex AS Autosampler, a CS16 $(4 \mathrm{~mm} \times 250 \mathrm{~mm}$ ) cation-separating analytical column, a cation self-regenerating suppressor (CSRS 300) operating at $79 \mathrm{~mA}$ and a suppressed conductivity detector (DS6 heated conductivity cell). The eluent was a $30 \mathrm{mM}$ aqueous solution of methanesulfonic acid (Merck) with a flow rate of $0.9 \mathrm{~mL} / \mathrm{min}$. For the analyses of carboxylic acids and sulfate ions, a Dionex ${ }^{\circledR}$ ICS 3000 ion chromatography system was used with a anion self-regenerating suppressor (ASRS 300) operating at $4 \mathrm{~mA}$, a conductometric detector, an AS11 column $\left(250 \times 250 \mathrm{~mm}^{2}\right)$ equipped with an AG11 guard column $\left(50 \times 4 \mathrm{~mm}^{2}\right)$ and a gradient of $\mathrm{KOH}$ (from $3 \mathrm{mM}$ to $60 \mathrm{mM}$ ) with a flow rate of $1.5 \mathrm{~mL} / \mathrm{min}$ during $40 \mathrm{~min}$. In the two cases, system operation control and data analysis was performed using commercial Chromeleon software. Calibration was performed using aqueous solutions of $\mathrm{NH}_{4} \mathrm{Cl}, \mathrm{CH}_{3} \mathrm{NH}_{3} \mathrm{Cl}$, $\left(\mathrm{CH}_{3}\right)_{2} \mathrm{NH}_{2} \mathrm{Cl},\left(\mathrm{CH}_{3}\right)_{3} \mathrm{NHCl}$ (Merck) in the concentration range between 0 and $500 \mu \mathrm{g} / \mathrm{L}$. Associated experimental errors are around $10 \%$.

\subsection{Experimental design}

The tutorials by Leardi (2009) and Lundstedt et al. (1998) give a simple and easily understandable introduction to experimental design and optimization by explaining the main concepts and applications of experimental design in chemistry and showing the real advantages in terms of reduced experimental effort and increased quality of information. Because of the cost and the run-time of the irradiations at high doses, this methodology was chosen to limit the number of experiments, carefully selected, to study the influence of several parameters (factors) on the behavior of three ion exchange resins exposed to $\gamma$-radiolysis under
Table 1

Influencing factors for the three studied resins.

\begin{tabular}{|c|c|c|c|c|}
\hline \multirow[t]{2}{*}{ Factors } & \multirow[t]{2}{*}{ Symbols } & \multicolumn{3}{|c|}{ Levels } \\
\hline & & No & Gas analyses & Solid analyses \\
\hline \multicolumn{5}{|l|}{$A m b O H$ and $A m b H\left(D_{2}\right)$} \\
\hline \multirow[t]{3}{*}{ Irradiation atmosphere } & $X_{1}$ & 1 & Oxygen & Air \\
\hline & & 2 & Argon & Argon \\
\hline & & 3 & Argon/water & Argon/water \\
\hline \multirow[t]{5}{*}{ Absorbed dose (MGy) } & $X_{2}$ & 1 & 0.1 & 0.1 \\
\hline & & 2 & 0.5 & 0.5 \\
\hline & & 3 & 1.0 & 1.0 \\
\hline & & 4 & 2.0 & 4.0 \\
\hline & & 5 & 3.0 & \\
\hline \multicolumn{5}{|l|}{ MB400 } \\
\hline \multirow{2}{*}{ Dose rate } & $X_{1}$ & 1 & $D_{1}$ & \\
\hline & & 2 & $D_{2}$ & \\
\hline \multirow[t]{3}{*}{ Irradiation atmosphere } & $X_{2}$ & 1 & Oxygen & Air \\
\hline & & 2 & Argon & Argon \\
\hline & & 3 & Argon/water & Argon/water \\
\hline \multirow[t]{5}{*}{ Absorbed dose (MGy) } & $X_{3}$ & 1 & 0.1 & 0.1 \\
\hline & & 2 & 0.5 & 0.5 \\
\hline & & 3 & 1.0 & 1.0 \\
\hline & & 4 & 2.0 & 4.0 \\
\hline & & 5 & 3.0 & \\
\hline
\end{tabular}

$D_{1}=0.35 \mathrm{kGy} / \mathrm{h}$ (low dose rate), $D_{2}=3.50 \mathrm{kGy} / \mathrm{h}$ (high dose rate).

different conditions. Three parameters were considered as potentially influential on the degradation of their chemical structure leading to gas production upon $\gamma$-rays. The variation range for each factor was determined based on simulated resin storage conditions and on experimental constraints of irradiators, and was described as follows: irradiation atmosphere (aerobic (oxygen or air), anaerobic (argon) or anaerobic with liquid water (argon with liquid water)), irradiation dose, and irradiation dose rate (low or high rate). The last factor was only taken into account in the MB400 study. The values of the second factor were $0.1,0.5,1.0$, 2.0 and 3.0 MGy for the gas analyses and 0.1, 0.5, 1.0 and 4 MGy in the solid study. The levels for operating conditions defined by the designs for the three resins are summarized in Table 1 . In the case of gas analyses, the selected output parameter (called response of experimental design, noted $Y$ ) was the formed gas concentration (in $\mathrm{mol} / \mathrm{kg}$ of irradiated resin) measured at the end of the irradiation cycle from mass spectrometry analyses. A screening study was first performed to get a preliminary idea of the effects of the chosen factors. Instead of a traditional "one factor at a time" approach, the experiments were carried out using experimental design to set up experiments in such a manner that the required information is obtained as efficiently and precisely as possible.

A screening study allows the direct comparison of two or more values and the postulated mathematical model is simply additive. The reduced reference state models used in a screening design for respectively 1 variable with 3 levels and 1 variable with 5 levels (AmbOH and AmbH model, Eq. (3)), or 1 variable with 2 levels, 1 variable with 3 levels and 1 variable with 5 levels (MB400 model, Eq. (4)) are the following:

$\eta=\beta_{0}+\beta_{1 \mathrm{~A}} X_{1 \mathrm{~A}}+\beta_{1 \mathrm{~B}} X_{1 \mathrm{~B}}+\beta_{2 \mathrm{~A}} X_{2 \mathrm{~A}}+\beta_{2 \mathrm{~B}} X_{2 \mathrm{~B}}+\beta_{2 \mathrm{C}} X_{2 \mathrm{C}}+\beta_{2 \mathrm{D}} X_{2 \mathrm{D}}$

$\eta=\beta_{0}+\beta_{1 \mathrm{~A}} X_{1 \mathrm{~A}}+\beta_{2 \mathrm{~A}} X_{2 \mathrm{~A}}+\beta_{2 \mathrm{~B}} X_{3 \mathrm{~B}}+\beta_{3 \mathrm{~A}} X_{3 \mathrm{~A}}+\beta_{3 \mathrm{~B}} X_{3 \mathrm{~B}}+\beta_{3 \mathrm{C}} X_{2 \mathrm{C}}+\beta_{3 \mathrm{D}} X_{3 \mathrm{D}}$

with $X_{i j}=1$ when the level $j$ of the variable $i$ is present and $=0$ for the other cases.

The coefficients $\beta_{i j}$ represent the variation of the response, replacing one level of the variable $i$, considered as a reference state (arbitrarily the last level), by the level $j$. 
To improve the estimation of the model coefficients, optimal designs of experiments (Addelman, 1962; Fedorov and Malyutov, 1972) were chosen: these asymmetrical designs $3^{1} 5^{1}$ and $2^{1} 3^{1} 5^{1}$ present respectively 14 and 17 experiments described in Table 1. The experiments are replicated to evaluate the variance of experimental error, leading to 28 experiments for anion and cation resins and 34 experiments for MB400 resin. From the experimental results for each studied response, the estimation of the model coefficients $\beta_{i j}$ is calculated by least squares regression.

From the values of these coefficients, it is possible to draw effect plots for the graphical representation of the behavior of the different levels for each variable.

The associated graph, appearing as a horizontal histogram, represents the calculated number of moles of molecular gases $\left(\mathrm{H}_{2 \mathrm{~g}}\right.$ or $\mathrm{TMA}_{\mathrm{g}}$ ) per kilogram of irradiated resin for the different levels of factors: dose rate (low and high), atmospheres (aerobic, anaerobic and anaerobic with water) and the absorbed doses (0.1, 0.5, 1.0, 2.0 and 3.0 MGy). The differences in the length of bars were used to evaluate the variation of the response according to the level of the considered factor. Visually, it allows to see if the amount of gas is modified by the variation of the factors to another. For an easier interpretation, tests of significance were performed from the experimental variance estimated with the replicates. Only the significant variations of the response are mentioned on the plots.

\subsection{Software}

NEMRODW software (LPRAI, Marseille, France) was developed for building and processing designs of experiments (Mathieu et al., 2000).

\section{Results and discussion}

Analysis of the experimentations revealed the presence of gaseous and water-soluble compounds came from the scission of the functional groups. In all irradiation atmospheres, the main detected gas was hydrogen. From Table 2, it was noted that the $G$ value of $\mathrm{H}_{2 \mathrm{~g}}$ was more important in the case of the gamma radiolysis of $\mathrm{AmbOH}$ under all the irradiation atmospheres. The $\mathrm{H}_{2 \mathrm{~g}}$ radiolytic yield of AmbOH increased with the absorbed dose in anaerobic and anaerobic/water conditions but the presence of water was not really significant on the $\mathrm{H}_{2 \mathrm{~g}}$ production. The $G$ values of $\mathrm{H}_{2 \mathrm{~g}}$ were in the same order for the AmbH and the MB400 resins with and without oxygen and kept almost constant when the absorbed dose increased. In presence of water, $G\left(\mathrm{H}_{2 \mathrm{~g}}\right)$ of $\mathrm{AmbH}$ was higher than under the other atmospheres. Contrary to what one might expect, $G\left(\mathrm{H}_{2 \mathrm{~g}}\right)$ of M400 in anaerobic with water environment was different from that of $\mathrm{AmbH}$ and showed a sharp increasing when the absorbed dose was superior at $3 \mathrm{MGy}$; at lower absorbed doses, this radiolytic yield remained relatively low. Carbon dioxide was found in quantitative amounts after radiolysis of the three resins in the presence of oxygen. $G\left(\mathrm{CO}_{2 \mathrm{~g}}\right)$ was detected for the $\mathrm{AmbOH}$ from an absorbed dose of $2 \mathrm{MGy}$ while the $\gamma$-irradiation of AmbH and MB400 resins generated an important quantity of carbon dioxide even at low doses. But only traces of $\mathrm{CO}_{2}$ were detected in anaerobic atmosphere with or without water in the case of the cation and mixed bed resins but the $G\left(\mathrm{CO}_{2 \mathrm{~g}}\right)$ could not be quantified. For $\mathrm{AmbOH}$, trimethylamine (TMA) was found in gaseous form when it was irradiated under anaerobic and aerobic conditions and in aqueous form under anaerobic conditions with liquid water. In the latter case, aqueous

Table 2

Radiolytic yields of formation $(X)$ or consumption $(-X)$ of compounds detected under the different irradiation atmospheres.

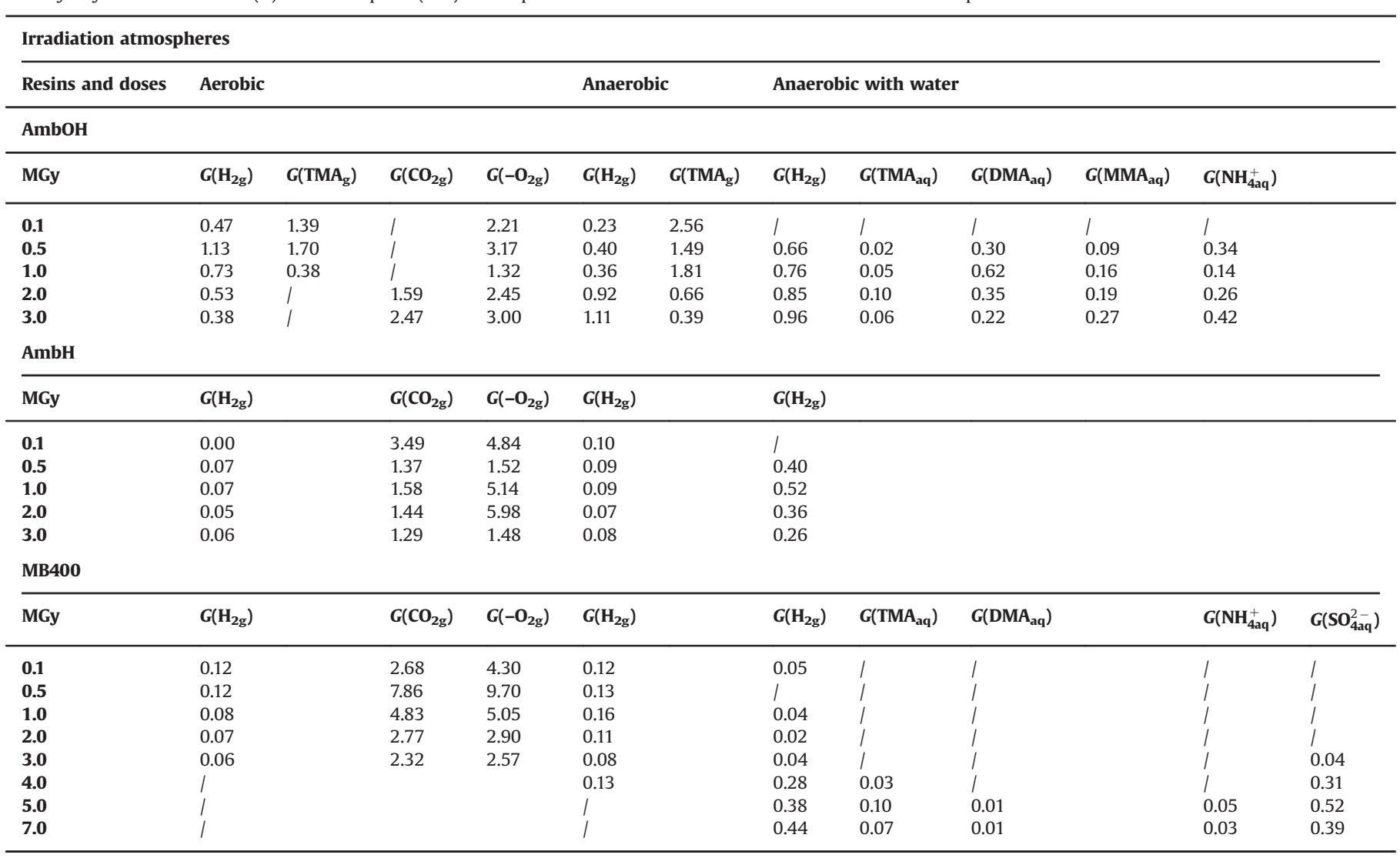

g: gaseous phase; aq: aqueous phase; G: radiolytic yield in molecules/100 eV; /: no detected. 
$\mathrm{TMA}_{\mathrm{aq}}$ was associated with other aqueous amines, dimethylamine $\left(\mathrm{DMA}_{\mathrm{aq}}\right)$, monomethylamine $\left(\mathrm{MMA}_{\mathrm{aq}}\right)$ and ammonia $\left(\mathrm{NH}_{4 \mathrm{aq}}^{+}\right)$. Under anaerobic and aerobic environments, $G\left(\mathrm{TMA}_{\mathrm{g}}\right)$ seemed to decrease when the absorbed dose increased because of the radiolytic decomposition of the functional groups of this resin. $G\left(\mathrm{TMA}_{\mathrm{g}}\right)$ of AmbOH became equal to zero from $2 \mathrm{MGy}$ in presence of oxygen, that was not observed in anaerobic atmosphere, showing that $\mathrm{TMA}_{\mathrm{g}}$ was severely degraded in presence of oxygen. Moreover, production yields of the different amines formed in aqueous solution varied in complex ways versus the absorbed dose. For $\mathrm{AmbH}$ and $\mathrm{MB} 400$ resins, sulfur dioxide $\left(\mathrm{SO}_{2 \mathrm{~g}}\right)$ was not detected but sulfate ions $\left(\mathrm{SO}_{4 \mathrm{aq}}^{2-}\right)$ were identified in the supernatant water and were only quantified for the mixed bed resin. Other gases such as carbon oxide $\left(\mathrm{CO}_{\mathrm{g}}\right)$, methane $\left(\mathrm{CH}_{4 \mathrm{~g}}\right)$, and ethane $\left(\mathrm{C}_{2} \mathrm{H}_{6 \mathrm{~g}}\right)$ were also detected but quantitative analysis was difficult because they were produced in very small quantities regardless of the irradiation atmosphere. In the case of the mixed bed resin (MB400), the degradation products were the same as those found after the radiolysis of pure resins (AmbOH and $\mathrm{AmbH}$ ). Some of the duplicates were not performed because of breakage of the glass tubes after irradiation, and the results of gaseous analyses are indicated in Tables 3 and 4 where the quantities are expressed per mole of kilogram of irradiated resin. In the case of TMA production during the $\mathrm{AmbOH}$ resin irradiation, the molar quantity of $\mathrm{TMA}_{\mathrm{g}}$ is indicated for aerobic and anaerobic atmospheres while the sum of the molar quantities of released amines is given for the anaerobic/water conditions to have data in all conditions as responses of experimental designs. The results of ion chromatography analyses are indicated in Table 5. The mole quantities (reported in Tables 3-5) were preferred to comment the behavior of the different resins after their gamma irradiation and to examine the impact of atmosphere, absorbed dose and the dose rate on the production of gas and no the radiolytic yield because its ratio cumulated the experimental errors of two measured data: the mole quantity and the absorbed dose and the variations of gaseous mole quantities were partially hidden by the increasing of the absorbed dose. In the screening of influencing factors on $\gamma$ radiolysis of the three resins, irradiation in anaerobic conditions will be considered as the reference atmosphere for comparison with the environments where liquid water and oxygen were present. Only data for the main detected gases $\left(\mathrm{H}_{2 \mathrm{~g}}\right.$ and $\left.\mathrm{TMA}_{\mathrm{g}}\right)$ were used as responses in the treatment of experimental designs.

From the experimental results of the 25 experiments performed on the anion resin $(\mathrm{AmbOH}), 21$ experiments for the cation resin $(\mathrm{AmbH})$ and 31 for $\mathrm{MB} 400$, the model coefficients were estimated, representing the variation of the response $\left(\mathrm{H}_{2 \mathrm{~g}}\right.$ and $\mathrm{TMA}_{\mathrm{g}}$ ) in comparison with the last level of each factor arbitrarily considered as reference.

For $\mathrm{TMA}_{\mathrm{g}}$ with anion resin, the regression coefficients of the model are as follows:

$y=0.205-0.130 X_{1 \mathrm{~A}}-0.031 X_{1 \mathrm{~B}}-0.118$

$X_{2 \mathrm{~A}}-0.067 X_{2 \mathrm{~B}}-0.029 X_{2 \mathrm{C}}-0.042 X_{2 \mathrm{D}}$

From this model, an effect plot can be used to visualize the behavior of each level of the studied factors (Fig. 1). In the case of the anion resin, known to be more easily degraded, the screening study shows that the atmosphere has an influence on TMA production. Considering the anaerobic atmosphere as a reference environment, the presence of oxygen significantly decreases the production of this gas (Fig. 1b) as shown by the significant

Table 3

Numerical designs, value of the responses for the three resins.

\begin{tabular}{|c|c|c|c|c|c|c|c|c|c|c|}
\hline \multicolumn{4}{|l|}{ AmbOH } & \multicolumn{3}{|l|}{ AmbH } & \multicolumn{4}{|l|}{ MB400 } \\
\hline Atm. & Dose (MGy) & $\mathrm{H}_{2 \mathrm{~g}}(\mathrm{~mol} / \mathrm{kg})$ & $\mathrm{TMA}_{\mathrm{g}}(\mathrm{mol} / \mathrm{kg})$ & Atm. & Dose (MGy) & $\mathrm{H}_{2 \mathrm{~g}}(\mathrm{~mol} / \mathrm{kg})$ & Dose rate & Atm. & Dose (MGy) & $\mathrm{H}_{2 \mathrm{~g}}(\mathrm{~mol} / \mathrm{kg})$ \\
\hline A & 0.1 & 0.010 & 0.014 & A & 0.1 & 0.000 & $D_{1}$ & A & 0.1 & 0.001 \\
\hline ANA & 0.1 & 0.000 & 0.026 & A & 0.1 & 0.000 & $D_{1}$ & A & 0.1 & 0.001 \\
\hline ANA & 0.1 & 0.000 & 0.026 & ANA & 0.1 & 0.001 & $D_{1}$ & ANA/W & 0.1 & 0.001 \\
\hline A & 0.5 & 0.060 & 0.009 & ANA & 0.1 & 0.001 & $D_{1}$ & ANA/W & 0.1 & 0.001 \\
\hline A & 0.5 & 0.060 & 0.086 & A & 0.5 & 0.003 & $D_{2}$ & ANA & 0.1 & 0.001 \\
\hline ANA & 0.5 & 0.020 & 0.084 & ANA & 0.5 & 0.005 & $D_{2}$ & ANA & 0.1 & 0.001 \\
\hline ANA & 0.5 & 0.020 & 0.064 & ANA & 0.5 & 0.004 & $D_{2}$ & ANA/W & 0.1 & 0.000 \\
\hline ANA/W & 0.5 & 0.040 & $0.04^{a}$ & ANA/W & 0.5 & 0.023 & $D_{1}$ & A & 0.5 & 0.006 \\
\hline A & 1.0 & 0.080 & 0.039 & ANA/W & 0.5 & 0.019 & $D_{1}$ & A & 0.5 & 0.007 \\
\hline ANA & 1.0 & 0.050 & 0.216 & A & 1.0 & 0.007 & $D_{2}$ & A & 0.5 & 0.006 \\
\hline ANA & 1.0 & 0.030 & 0.191 & ANA & 1.0 & 0.012 & $D_{2}$ & A & 0.5 & 0.007 \\
\hline ANA & 1.0 & 0.040 & 0.187 & ANA/W & 1.0 & 0.054 & $D_{2}$ & ANA & 0.5 & 0.008 \\
\hline ANA/W & 1.0 & 0.090 & $0.10^{\mathrm{a}}$ & A & 2.0 & 0.011 & $D_{2}$ & ANA & 0.5 & 0.006 \\
\hline ANA/W & 1.0 & 0.070 & $0.095^{\mathrm{a}}$ & ANA & 2.0 & 0.014 & $D_{1}$ & A & 1.0 & 0.008 \\
\hline A & 2.0 & 0.110 & 0.000 & ANA/W & 2.0 & 0.079 & $D_{1}$ & A & 1.0 & 0.009 \\
\hline A & 2.0 & 0.110 & 0.000 & ANA/W & 2.0 & 0.072 & $D_{1}$ & ANA/W & 1.0 & 0.006 \\
\hline ANA & 2.0 & 0.190 & 0.126 & A & 3.0 & 0.019 & $D_{1}$ & ANA/W & 1.0 & 0.003 \\
\hline ANA & 2.0 & 0.190 & 0.147 & ANA & 3.0 & 0.023 & $D_{2}$ & ANA & 1.0 & 0.017 \\
\hline ANA/W & 2.0 & 0.170 & $0.181^{\mathrm{a}}$ & ANA & 3.0 & 0.021 & $D_{2}$ & ANA & 1.0 & 0.018 \\
\hline ANA/W & 2.0 & 0.180 & $0.198^{a}$ & ANA/W & 3.0 & 0.083 & $D_{2}$ & ANA/W & 1.0 & 0.005 \\
\hline A & 3.0 & 0.120 & 0.000 & ANA/W & 3.0 & 0.076 & $D_{2}$ & ANA/W & 1.0 & 0.003 \\
\hline A & 3.0 & 0.120 & 0.000 & & & & $D_{2}$ & A & 2.0 & 0.017 \\
\hline ANA & 3.0 & 0.350 & 0.123 & & & & $D_{2}$ & A & 2.0 & 0.014 \\
\hline ANA/W & 3.0 & 0.300 & $0.317^{\mathrm{a}}$ & & & & $D_{2}$ & ANA & 2.0 & 0.022 \\
\hline \multirow[t]{7}{*}{ ANA/W } & 3.0 & 0.360 & $0.292^{\mathrm{a}}$ & & & & $D_{2}$ & ANA/W & 2.0 & 0.005 \\
\hline & & & & & & & $D_{2}$ & ANA/W & 2.0 & 0.004 \\
\hline & & & & & & & $D_{2}$ & A & 3.0 & 0.018 \\
\hline & & & & & & & $D_{2}$ & A & 3.0 & 0.019 \\
\hline & & & & & & & $D_{2}$ & ANA & 3.0 & 0.027 \\
\hline & & & & & & & $D_{2}$ & ANA & 3.0 & 0.026 \\
\hline & & & & & & & $D_{2}$ & ANA/W & 3.0 & 0.011 \\
\hline
\end{tabular}

Atm.: irradiation atmosphere; A: aerobic; ANA: anaerobic; ANA/W: anaerobic/water;

Dose rates: $D_{1}=0.35 \mathrm{kGy} / \mathrm{h}$ or $D_{2}=3.50 \mathrm{kGy} / \mathrm{h} \mathrm{mol} / \mathrm{kg}$ : moles quantity per kilogram of irradiated resin.

a Sum of moles quantity of released amines in water $=n\left(\mathrm{TMA}_{\mathrm{aq}}\right)+n\left(\mathrm{DMA}_{\mathrm{aq}}\right)+n\left(\mathrm{MMA}_{\mathrm{aq}}\right)+n\left(\mathrm{NH}_{4 \mathrm{aq}}^{+}\right)$. 
Table 4

Results of $\mathrm{CO}_{2}$ analyses.

\begin{tabular}{|c|c|c|c|c|c|c|c|c|}
\hline \multicolumn{9}{|c|}{$\mathrm{CO}_{2}(\mathrm{~mol} / \mathrm{kg}$ of irradiated resin) } \\
\hline Irradiation Atm. & Dose rate & Dose (MGy) & AmbOH & AmbH & Irradiation atm. & Dose rate & Dose (MGy) & MB400 \\
\hline A & $D_{2}$ & 0.1 & 0.000 & 0.036 & A & $D_{1}$ & 0.1 & 0.000 \\
\hline ANA & $D_{2}$ & 0.1 & 0.000 & 0.000 & ANA/W & $D_{1}$ & 0.1 & 0.000 \\
\hline A & $D_{2}$ & 0.5 & 0.000 & 0.071 & ANA & $D_{2}$ & 0.1 & 0.000 \\
\hline ANA & $D_{2}$ & 0.5 & 0.000 & 0.000 & ANA/W & $D_{2}$ & 0.1 & 0.000 \\
\hline ANA/W & $D_{2}$ & 0.5 & 0.000 & 0.003 & A & $D_{1}$ & 0.5 & 0.007 \\
\hline A & $D_{2}$ & 1.0 & 0.000 & 0.164 & ANA & $D_{2}$ & 0.5 & 0.010 \\
\hline ANA & $D_{2}$ & 1.0 & 0.000 & 0.000 & A & $D_{2}$ & 0.5 & 0.007 \\
\hline ANA/W & $D_{2}$ & 1.0 & 0.000 & 0.005 & ANA & $D_{1}$ & 0.5 & 0.007 \\
\hline A & $D_{2}$ & 3.0 & 0.750 & 0.426 & A & $D_{1}$ & 1.0 & 0.009 \\
\hline ANA & $D_{2}$ & 3.0 & 0.000 & 0.000 & ANA/W & $D_{2}$ & 1.0 & 0.005 \\
\hline \multirow[t]{5}{*}{ ANA/W } & $D_{2}$ & 3.0 & 0.000 & 0.011 & ANA & $D_{2}$ & 1.0 & 0.018 \\
\hline & & & & & ANA/W & $D_{2}$ & 1.0 & 0.004 \\
\hline & & & & & A & $D_{2}$ & 3.0 & 0.018 \\
\hline & & & & & ANA & $D_{2}$ & 3.0 & 0.027 \\
\hline & & & & & ANA/W & $D_{2}$ & 3.0 & 0.011 \\
\hline
\end{tabular}

Atm.: atmosphere; A: aerobic; ANA: anaerobic; ANA/W: anaerobic/water;

Dose rates: $D_{1}=0.35 \mathrm{kGy} / \mathrm{h}$ or $D_{2}=3.50 \mathrm{kGy} / \mathrm{h}$.

Table 5

Results of amines and sulfate analyses.

\begin{tabular}{|c|c|c|c|c|c|c|}
\hline \multicolumn{7}{|c|}{ Amines and sulfate quantities under anaerobic/water atmosphere } \\
\hline $\begin{array}{l}\text { Dose } \\
\text { rate } \\
(\mathbf{k G y} / \mathbf{h})\end{array}$ & $\begin{array}{l}\text { Dose } \\
\text { (MGy) }\end{array}$ & TMA $_{\mathrm{aq}}$ & $\mathrm{DMA}_{\mathrm{aq}}$ & $\begin{array}{l}\mathrm{MMA}_{\mathrm{aq}} \\
\text { (mol/kg of } \\
\text { irradiated } \\
\text { resin) }\end{array}$ & $\mathbf{N H}_{4 a q}^{+}$ & $\mathrm{SO}_{4 a q}^{2-}$ \\
\hline \multicolumn{7}{|l|}{ AmbOH } \\
\hline$D_{2}$ & 0.5 & 0.001 & 0.016 & 0.016 & 0.018 & \\
\hline$D_{2}$ & 1.0 & 0.004 & 0.066 & 0.066 & 0.013 & \\
\hline$D_{2}$ & 1.0 & 0.007 & 0.059 & 0.059 & 0.014 & \\
\hline$D_{2}$ & 2.0 & 0.017 & 0.071 & 0.071 & 0.053 & \\
\hline$D_{2}$ & 2.0 & 0.024 & 0.075 & 0.075 & 0.057 & \\
\hline$D_{2}$ & 3.0 & 0.021 & 0.073 & 0.073 & 0.133 & \\
\hline$D_{2}$ & 3.0 & 0.018 & 0.063 & 0.063 & 0.130 & \\
\hline \multicolumn{7}{|l|}{ AmbH } \\
\hline$D_{2}$ & 0.5 & & & & & 0.111 \\
\hline$D_{2}$ & 0.5 & & & & & 0.101 \\
\hline$D_{2}$ & 1.0 & & & & & 0.202 \\
\hline$D_{2}$ & 2.0 & & & & & 0.282 \\
\hline$D_{2}$ & 2.0 & & & & & 0.241 \\
\hline$D_{2}$ & 3.0 & & & & & 0.292 \\
\hline$D_{2}$ & 3.0 & & & & & 0.282 \\
\hline \multicolumn{7}{|l|}{ MB400 } \\
\hline$D_{1}$ & 0.1 & 0.000 & 0.000 & 0.000 & 0.005 & 0.000 \\
\hline$D_{2}$ & 0.1 & 0.000 & 0.000 & 0.000 & 0.007 & 0.000 \\
\hline$D_{1}$ & 1.0 & 0.000 & 0.000 & 0.000 & 0.004 & 0.000 \\
\hline$D_{2}$ & 1.0 & 0.000 & 0.000 & 0.000 & 0.007 & 0.000 \\
\hline$D_{2}$ & 2.0 & 0.000 & 0.000 & 0.000 & 0.004 & 0.004 \\
\hline$D_{2}$ & 3.0 & 0.004 & 0.000 & 0.000 & 0.007 & 0.014 \\
\hline$D_{2}$ & 4.0 & 0.041 & 0.010 & 0.003 & 0.027 & 0.122 \\
\hline
\end{tabular}

Dose rates: $D_{1}=0.35 \mathrm{kGy} / \mathrm{h}$ or $D_{2}=3.50 \mathrm{kGy} / \mathrm{h}$.

coefficient. The first hypothesis could be that oxygen dissolved in water consumes some solvated electrons produced by radiolysis of hydrated water, as described in the following equation:

$\mathrm{e}_{\text {solv }}^{-}+\mathrm{O}_{2 \mathrm{aq}} \rightarrow \mathrm{O}_{2 \mathrm{aq}}^{-}$

This reaction is in competition with the deamination process proposed by the same authors and due to the interaction of the quaternary ammonium group as shown by the following reaction:

$\mathrm{e}_{\text {solv }}^{-}+\mathrm{Ar}-\mathrm{CH}_{2}-\mathrm{N}^{+}\left(\mathrm{CH}_{2}\right)_{3} \rightarrow \mathrm{Ar}-\mathrm{CH}_{2}+\mathrm{N}\left(\mathrm{CH}_{2}\right)_{3}$ a

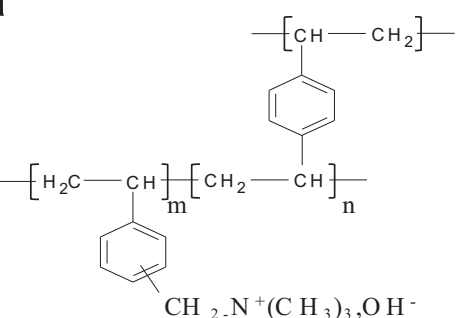

b

ATMOSPHERES

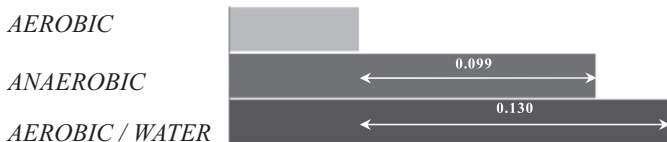

ABSORBED DOSE

$0.1 \mathrm{MGy}$

0.5 MGy

$1.0 \mathrm{MGy}$

2.0 MGy

3.0 MGy

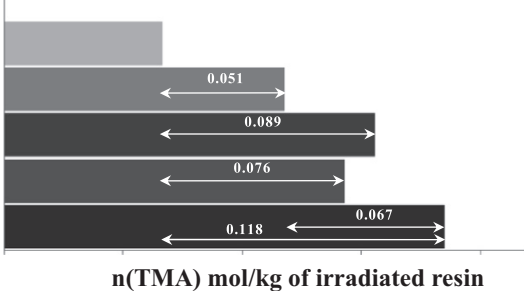

Fig. 1. TMA production responses for AmbOH structure (a) and effect plot (b).

As the degradation of functional groups is less easy than in anaerobic atmosphere, the $\mathrm{TMA}_{\mathrm{g}}$ production is lower.

The second explanation could involve oxidation of the functional groups, decreasing the quantity of $\mathrm{TMA}_{\mathrm{g}}$. A specific detailed study of the effect of $\gamma$-radiolysis on the $\mathrm{AmbOH}$ structure (Traboulsi et al., 2012) showed the possible oxidation of the quaternary ammonium groups of this resin in aerobic atmosphere at high dose. Moreover, the graph reveals that the presence of liquid water slightly increases the quantity of aqueous amines. In this case the solvated electrons react with the functional groups leading to a deamination reaction, which increases the quantity of aqueous amines. The effect of the absorbed dose is less important. The dose at 0.1 MGy considered as the reference dose has the lowest response while the dose at 3.0 MGy has the highest TMA quantity and the other doses are similar. 
a

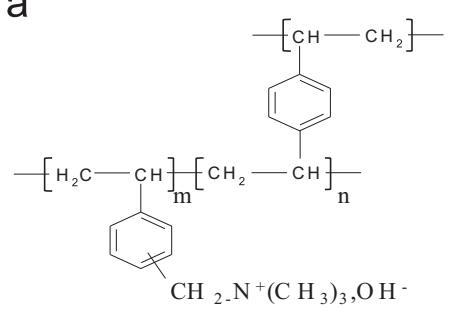

b

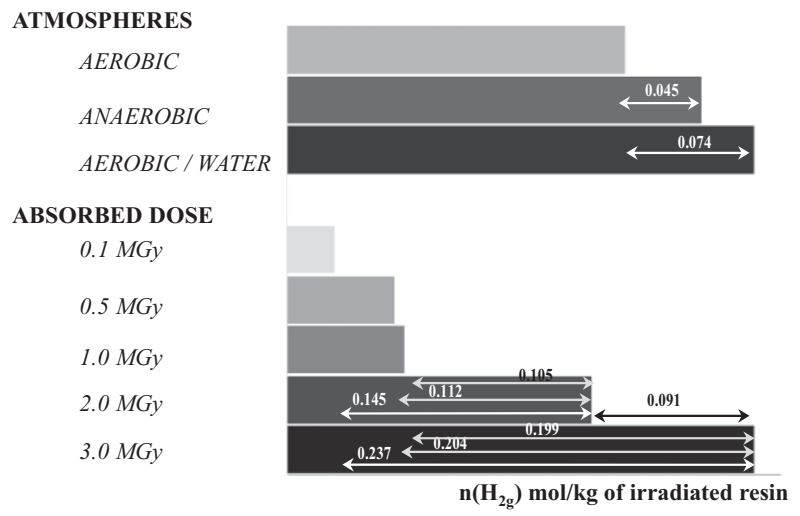

Fig. 2. $\mathrm{H}_{2 \mathrm{~g}}$ production responses for AmbOH structure (a) and effect plot (b).

The regression coefficients of the model for hydrogen production during $\mathrm{AmbOH}$ radiolysis are:

$y=0.285-0.074 X_{1 \mathrm{~A}}-0.029 X_{1 \mathrm{~B}}-0.237 X_{2 \mathrm{~A}}-0.204$

$X_{2 \mathrm{~B}}-0.199 X_{2 \mathrm{C}}-0.091 X_{2 \mathrm{D}}$

The three tested atmospheres respond differently in comparison with the reference atmosphere, as observed on Fig. 2. The relative magnitude of each atmosphere on the bar plot (Fig. 2b) shows that the presence of oxygen slightly decreases the $\mathrm{H}_{2 \mathrm{~g}}$ production although the presence of water does not significantly modify the resin behavior relative to the reference environment. As previously, an explanation could be that the presence of oxygen oxidized the structure of AmbOH resin, which generated less TMA and derivative compounds known to produce $\mathrm{H}_{2 \mathrm{~g}}$ during their degradation (Ahmed et al., 1966; Traboulsi et al, 2012; Hall and Streat, 1963). Pure water $\gamma$-radiolysis is generally known to generate $\mathrm{H}_{2 \mathrm{~g}}$ (Yamada et al., 2008, 2011) but in our case, in presence of the solid resin, water radiolysis took place in a different way because its precursors, $\mathrm{H}$. and $\mathrm{e}_{\text {solv }}^{-}$, could react with the solid resin, decreasing their recombination probability, i.e. the $\mathrm{H}_{2 \mathrm{~g}}$ production. There could be competition between the reactions of $e_{\text {solv }}^{-}$recombination (Eqs. (9) and (10)) and the deamination process (Eq. (7)) controlled by $\mathrm{e}_{\text {solv }}^{-}$diffusion:

$\mathrm{e}_{\text {solv }}^{-}+\mathrm{e}_{\text {solv }}^{-}+2 \mathrm{H}_{2} \mathrm{O} \rightarrow \mathrm{H}_{2 \mathrm{~g}}+2 \mathrm{OH}^{-}$

$\mathrm{H}^{+}+\mathrm{e}_{\text {solv }}^{-}+\mathrm{H}_{2} \mathrm{O} \rightarrow \mathrm{H}_{2 \mathrm{~g}}+\mathrm{OH}^{-}$

The heterogeneous environment could influence the diffusion distance of the primary products of water radiolysis $\left(\mathrm{H}^{\bullet}\right.$ and $\left.\mathrm{e}_{\text {solv }}^{-}\right)$ and promote their recombination with their parent molecules to the detriment of $\mathrm{H}_{2 \mathrm{~g}}$ formation (Le Caër et al., 2005). With regard to the dose influence, where 0.1 MGy was considered as the reference value, gamma radiolysis of this resin produced comparable hydrogen quantity at irradiation doses below $1 \mathrm{MGy}$, but from 2 MGy the hydrogen production increased considerably with the dose.

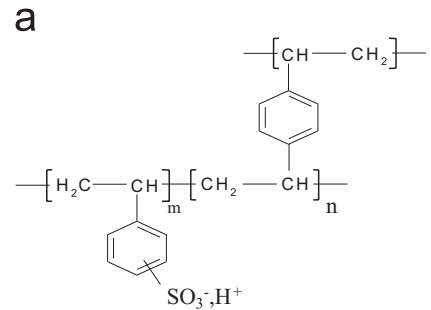

b

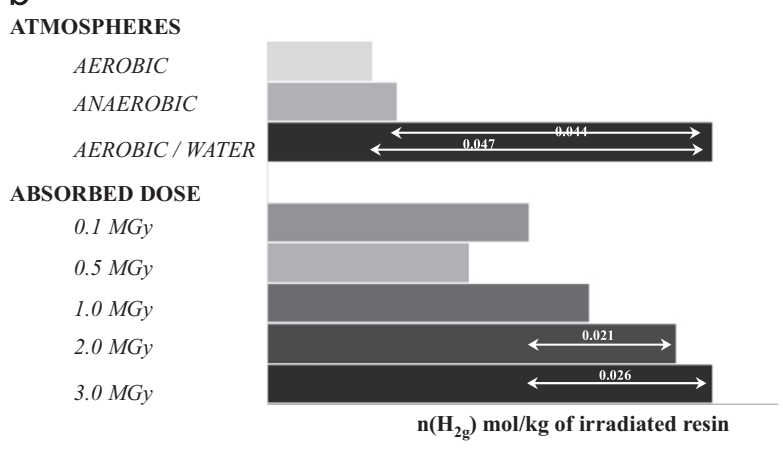

Fig. 3. $\mathrm{H}_{2 \mathrm{~g}}$ production responses for AmbH structure (a) and effect plot (b).

The regression coefficients of the model for hydrogen production for the cation resin $(\mathrm{AmbH})$ are as follows:

$y=0.071-0.047 X_{1 \mathrm{~A}}-0.044 X_{1 \mathrm{~B}}-0.026 X_{2 \mathrm{~A}}-0.034$

$X_{2 \mathrm{~B}}-0.017 X_{2 \mathrm{C}}-0.005 X_{2 \mathrm{D}}$

The model indicates a significant influence of the irradiation atmosphere. Fig. 3 shows that aerobic and anaerobic environments have the same behavior (no significant variation) while anaerobic atmosphere with liquid water gave significantly different results. Molecular hydrogen was produced in the same quantity in aerobic and aerobic atmospheres, but the presence of water increased mainly the $\mathrm{H}_{2 \mathrm{~g}}$ formation. The similar behavior in aerobic and anaerobic atmospheres is probably due to the relative stability of AmbH resin in the studied dose range. Its degradation at 3 MGy might not be sufficient to observe an effect of the irradiation atmosphere. These results are consistent with the work of Swyler et al. (1983a). The increased $\mathrm{H}_{2 \mathrm{~g}}$ production in presence of liquid water could be due to $\gamma$-radiolysis of sulfuric acid $\left(\mathrm{SO}_{4 \mathrm{aq}}^{2-}, 2 \mathrm{H}_{\mathrm{aq}}^{+}\right)$ formed in the liquid in contact with the irradiated resin after the scission of its $-\mathrm{SO}_{3} \mathrm{H}$ functional group. Studies on radiolysis of sulfuric acid solutions (Yamada et al., 2008; Garett et al., 2005; Lesigne et al., 1973) confirmed the production of hydrogen gas resulting in the recombination of hydrogen radical according the following reactions:

$\mathrm{H}^{+}+\mathrm{e}_{\text {solv }}^{-} \rightarrow \mathrm{H}^{\bullet}$

$\mathrm{H}^{\bullet}+\mathrm{H}^{\bullet} \rightarrow \mathrm{H}_{2 \mathrm{~g}}$

where $e_{\text {solv }}^{-}$came from water radiolysis. The presence of sulfuric acid in our aqueous phases was confirmed by the acidic $\mathrm{pH}(<1)$. Few differences in $\mathrm{H}_{2 \mathrm{~g}}$ production were observed under irradiation doses of 0.1, 0.5 and 1.0 MGy: compared with the reference dose (0.1 MGy), the variation of the response is not statistically significant. Nevertheless, compared with the reference dose (0.1 MGy) the significant coefficients (respectively equal to 0.021 and 0.026 ), proving that the amount of $\mathrm{H}_{2 \mathrm{~g}}$ increased rapidly from 2 MGy. Above this dose, the $\mathrm{H}_{2 \mathrm{~g}}$ production is stable because the effect corresponding at the increasing of the absorbed dose (from 2 to $3 \mathrm{MGy}$ ) is no significant: the variation of the response, equal to 0.005 , is in the confidence interval, then the effect must be considered as negligible. 


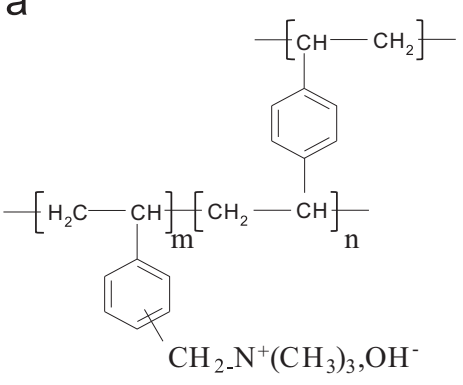

$25 \% \mathrm{AmbOH}$

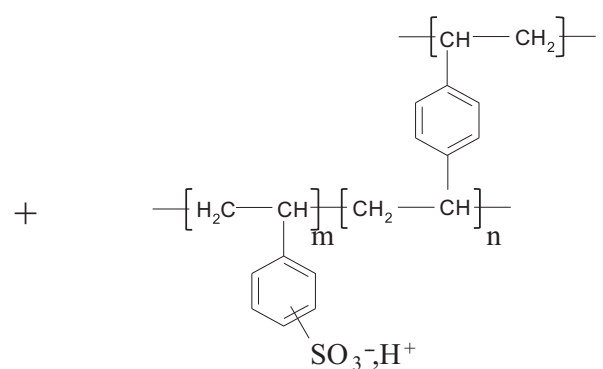

$75 \% \mathrm{AmbH}$

b

DOSE RATE

$L O W$

$H I G H$

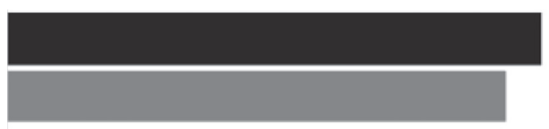

ATMOSPHERES

AEROBIC

ANAEROBIC

AEROBIC / WATER

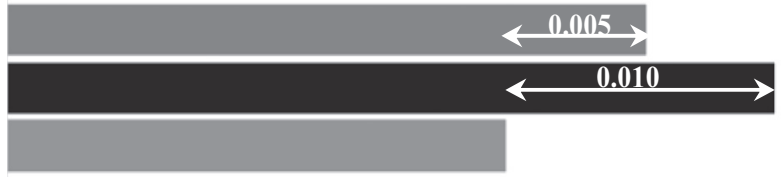

ABSORBED DOSE

$$
\begin{aligned}
& 0.1 M G y \\
& 0.5 M G y \\
& 1.0 M G y \\
& 2.0 M G y \\
& 3.0 M G y
\end{aligned}
$$

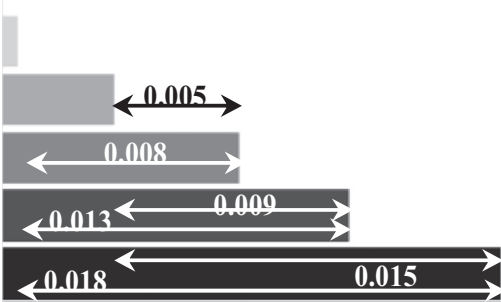

$$
\mathbf{n}\left(\mathrm{H}_{2 \mathrm{~g}}\right) \mathrm{mol} / \mathrm{kg} \text { of irradiated resin }
$$

Fig. 4. $\mathrm{H}_{2 \mathrm{~g}}$ production responses for MB400 structure (a) and effect plot (b).

For the mixed bed resin (MB400), the estimation of the coefficients calculated from the 31 experiments gives the following model:

$y=0.0134+0.0014 X_{1 \mathrm{~A}}+0.0053 X_{2 \mathrm{~A}}+0.0102$

$X_{2 \mathrm{~B}}-0.0184 X_{3 \mathrm{~A}}-0.0147 X_{3 \mathrm{~B}}-0.0099 X_{3 \mathrm{C}}-0.0058 X_{3 \mathrm{D}}$

Fig. 4 reveals that the dose rate factor has no effect on the response: a low or high dose rate did not modify the generated hydrogen quantity (no significant variation of the response). Same results were also obtained by Swyler et al. (1983a). Concerning the impact of the absorbed dose, the behavior of the five levels increased with the value of the absorbed dose: the $\mathrm{H}_{2 \mathrm{~g}}$ quantity increased regularly with the absorbed doses between 0.1 and 3 MGy. The variation of the response is becoming more significant. The difference between the "anaerobic" and "aerobic" levels is slightly significant. The smaller quantity of $\mathrm{H}_{2 \mathrm{~g}}$ could be due to oxidation of the MB400 structure: the degradation occurred on the $\mathrm{AmbOH}$ backbone. The high difference between the anaerobic atmospheres with and without water reveals that $\mathrm{H}_{2 \mathrm{~g}}$ production decreased in the presence of water. Under these irradiation conditions, commercial resin seemed to follow a different way of degradation because of possible interactions between $\mathrm{AmbOH}$ and AmbH resins.

The separate studies on pure resins confirmed a different behavior due to their functional groups, which were degraded differently by gamma irradiation. But when the pure resins are in mixed bed, they do not appear to react in the same way because MB400 resin shows a different behavior towards gamma irradiation. The behavior of MB400 resin formed with $75 \mathrm{wt} \% \mathrm{AmbH}$ and $25 \mathrm{wt} \% \mathrm{AmbOH}$ could be expected to correspond to the sum of the behavior of the separated resins ( $\mathrm{AmbH}$ and $\mathrm{AmbOH}$ ) according to their respective quantities: gamma radiolysis of commercial resin would then generate the same products according to the relative proportions of $\mathrm{AmbOH}$ and $\mathrm{AmbH}$. But this hypothesis is not verified because TMAg has not been identified as a radiolysis gas of MB400 resin. The maximum quantity of $\mathrm{TMA}_{\mathrm{g}}$ produced after AmbOH irradiation was near $0.2 \mathrm{~mol} / \mathrm{kg}$ of resin (at $1 \mathrm{MGy}$ in anaerobic environment). Assuming simple additive behavior of $\mathrm{AmbOH}$ resin in the mixed resin, MB400 resin should generate $25 \%$ of that quantity (about $0.05 \mathrm{~mol} / \mathrm{kg}$ of resin) or more. Moreover, if we compare the screening study of factors influencing the $\mathrm{H}_{2 \mathrm{~g}}$ production for each resin (Fig. 2b, Fig. 3b and Fig. 4b), it is clear that the MB400 behavior is not only the weighted sum of its components. A new parameter must be considered to explain this phenomenon: the nature of the resin. To quantify the effect of the resin, taking into account the "atmosphere/resin nature" and "dose/resin nature" interaction effects, the three screening designs for a same high dose rate have been gathered, considering the nature of the resin as a factor. This design with 3 factors $\left(X_{1}\right.$ : Resin, $X_{2}$ : Atmosphere, $X_{3}$ : absorbed dose) consists of 67 experiments with duplicates and can be interpreted with a synergic model considering the interactions with the nature of the resin. The 
a

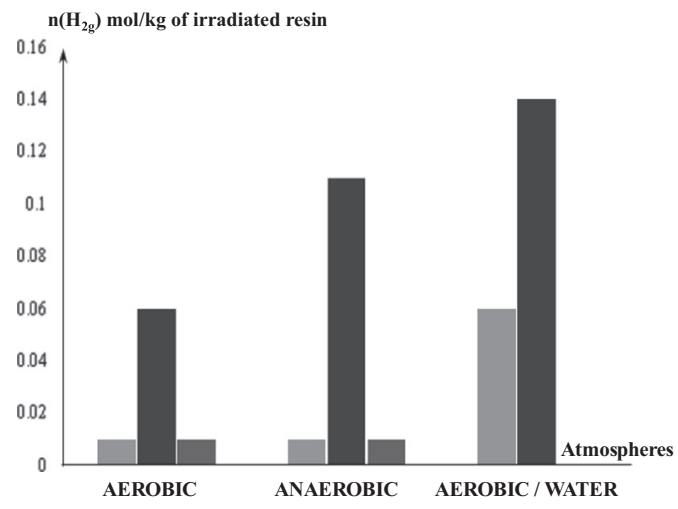

b

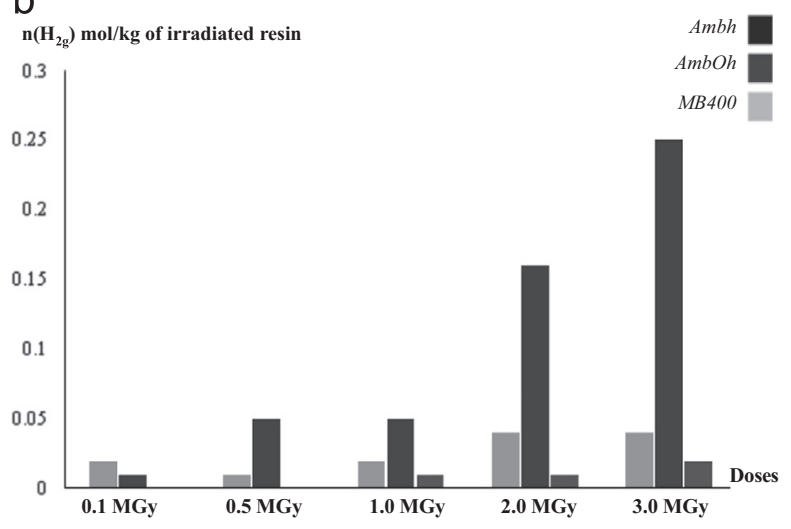

Fig. 5. Interaction plots: resins/atmosphere (a) and resins/doses (b).

estimation of the coefficients of this model is:

$y=0.0460-0.0209 X_{1 A}+0.0576 X_{1 B}-0.0183$

$X_{2 A}-0.0010 X_{2 B}-0.0367 X_{3 A}-0.0271 X_{3 B}-0.0172$

$X_{3 C}+0.0237 X_{3 D}+0.0015 X_{1 A} X_{2 A}-0.0124 X_{1 A} X_{2 B}-0.0214$

$X_{1 B} X_{2 A}+0.0062 X_{1 B} X_{2 B}+0.0273 X_{1 A} X_{3 A}+0.0095$

$X_{1 A} X_{3 B}+0.0165 X_{1 A} X_{3 C}-0.0122 X_{1 A} X 3 D-0.0541$

$X_{1 B} X_{3 A}-0.0306 X_{1 B} X_{3 B}-0.0360 X_{1 B} X_{3 C}+0.0318 X_{1 B} X_{3 D}$

This model can be interpreted with interaction diagrams showing that the behavior of the atmosphere and absorbed dose factors depends on the resin.

Fig. $5 \mathrm{a}$ and $\mathrm{b}$ shows that the atmosphere factor appears to influence mainly the cation resin for which the response is significant in anaerobic atmosphere with liquid water. The effect is weaker for the other two samples (Fig. 5a). The dose impact (Fig. 5b) is notable for anion resin. This sample has the same behavior at low doses (0.1, 0.5 and $1 \mathrm{MGy}$ ) but its degradation increases significantly with the dose (above $2 \mathrm{MGy}$ ). In a mixed bed, this resin appears to be more resistant to radiolysis because of its mass percentage ( $25 \mathrm{wt} \%$ ) and its near field environment with the cation resin. The quantity of $\mathrm{H}_{2 \mathrm{~g}}$ increases slightly with the dose in the case of the cation resin. In spite of the percentage of each resin in the mixed bed, the MB400 sample produces less molecular hydrogen than the pure resins irradiated separately. And the expected $\mathrm{H}_{2 \mathrm{~g}}$ quantity is less than that calculated by taking into account the relative percentages of anion and cation resins in the MB400 sample (25 wt\% and $75 \mathrm{wt} \%$, respectively). There appears to be a protective matrix effect: in a mixed bed, the pure resins appear to be less degraded.

These gases were obtained in variable quantities in three irradiation atmospheres, which implies different resin degradation mechanisms. Taking into account the identified species from Mass Spectroscopy and Ionic Chromatography analyses, possible steps proposed for AmbOH degradation under our experimental $\gamma$-irradiations are indicated in Fig. 6a. Molecular hydrogen and trimethylamine were produced under all irradiation conditions. Under anaerobic and aerobic $\gamma$-irradiations, $G\left(\mathrm{TMA}_{\mathrm{g}}\right)$ decreased with the absorbed dose because of its degradation under gamma rays (Baidak and LaVerne, 2010; Sami and Smithies, 1974). Its $\gamma$-decomposition could explain the formation of $\mathrm{CH}_{4 \mathrm{~g}}$ traces (around of $10^{-2}$ and $2 \times 10^{-3} \mathrm{~mol} / \mathrm{kg}$ of irradiated resin at high absorbed doses) because of its demethylation (Takamuku and Sakurai, 1965). Moreover $\mathrm{CH}_{4 \mathrm{~g}}$ could be likely to be degraded occurring the formation of $\mathrm{C}_{2} \mathrm{H}_{6 \mathrm{~g}}$ traces (around of $2 \times 10^{-3}$ and $10^{-3} \mathrm{~mol} / \mathrm{kg}$ of irradiated resin in anaerobic environment and in presence of oxygen, respectively), resulting of the recombination of radiolysis products of $\mathrm{CH}_{4 \mathrm{~g}}$ as $\mathrm{CH}_{3}$ (Myers and Schmidt-Bleek, 1967). Also, TMA could be further degraded, resulting in the formation of additional $\mathrm{H}_{2 \mathrm{~g}}$, as well as other gases including
$\mathrm{CH}_{4 \mathrm{~g}}, \mathrm{C}_{2} \mathrm{H}_{4 \mathrm{~g}}, \mathrm{CO}_{2 \mathrm{~g}}$. In presence of liquid water, TMAg was absent because of its high solubility in water and $\mathrm{TMA}_{\mathrm{aq}}$ was associated with other amines. The concentration of $\mathrm{TMA}_{\mathrm{aq}}$ and $\mathrm{DMA}_{\mathrm{aq}}$ evolved in parallel increasing until $2 \mathrm{MGy}$ then decreased after this dose. The concentration of $\mathrm{MMA}_{\mathrm{aq}}$ and $\mathrm{NH}_{4 \mathrm{aq}}^{+}$increased rapidly between 0.5 and 3 MGy then they were constant until 4 MGy. We can suppose that $\mathrm{MMA}_{\mathrm{aq}}$ and $\mathrm{NH}_{4 \mathrm{aq}}^{+}$were secondary products no resulting of the direct degradation of $\mathrm{AmbOH}$ resin. Also, $\mathrm{TMA}_{\mathrm{aq}}$ and $\mathrm{DMA}_{\mathrm{aq}}$ could be at the origin of the formation $\mathrm{MMA}_{\mathrm{aq}}$ and $\mathrm{NH}_{4 \mathrm{aq}}^{+}$. The presence of $\mathrm{DMA}_{\mathrm{aq}}$ was due to the demethylation of functional groups $\left(-\mathrm{N}^{+}\left(\mathrm{CH}_{3}\right)_{3}\right)$ and was favored in presence of water as it was shown in the literature (Hall and Streat, 1963; Ahmed et al., 1966; Baidak and LaVerne, 2010, Kiseleva et al., 1970). The mechanisms proposed by these authors for the formation of theses amines involved the formation of $\mathrm{CH}_{4 \mathrm{~g}}$ and formaldehyde $\left(\mathrm{CH}_{2} \mathrm{O}_{\mathrm{aq}}\right)$ that were detected in very small amounts in our case. $\mathrm{CO}_{2 \mathrm{~g}}$ appeared only under aerobic conditions where its precursor could be the carboxyl radical RCOO` (Dely et al., 2008) resulting in the oxidation of the resin groups. Its degradation involved $\mathrm{CO}_{2 \mathrm{~g}}$ formation as described in following equation:

$\mathrm{RCOO}^{*} \rightarrow \mathrm{CO}_{2 \mathrm{~g}}+\mathrm{R}^{\cdot}$

The backbone is not at the origin of $\mathrm{CO}_{2 \mathrm{~g}}$ production because of the stability of aromatic cycles. The methane arising from $\mathrm{TMA}_{\mathrm{g}}$ degradation could also generate this gas (Lind, 1961) as follows:

$\mathrm{CH}_{4}+\mathrm{CH}_{4}+2 \mathrm{O}_{2 \mathrm{~g}} \rightarrow \mathrm{CO}_{2 \mathrm{~g}}+2 \mathrm{H}_{2} \mathrm{O}$

In the case of $\mathrm{AmbH}$, Fig. 6b summarizes the hypotheses concerning the degradation of the functional groups of this resin. Molecular hydrogen was the only detected gas. No trace of $\mathrm{SO}_{2 \mathrm{~g}}$ has been found. Its formation has been rarely reported in the literature (Pillay, 1986). In anaerobic or aerobic environments, if $\mathrm{SO}_{2 \mathrm{~g}}$ was formed, it was trapped in the interstitial water because of its high solubility in water and appeared in ionic form $\left(\mathrm{SO}_{4 \mathrm{aq}}^{2-}\right)$. After the leaching of these irradiated resins in water, a decrease of the $\mathrm{pH}$ value was observed with the increase of the absorbed dose. In the case of the resins irradiated under anaerobic/water conditions, the measured $\mathrm{pH}$ (near of 2) of the supernatant liquid in contact with the resin also confirmed the existence of acidic forms $\left(\mathrm{SO}_{4 \mathrm{aq}}^{2-}, \mathrm{H}_{\mathrm{aq}}^{+}\right.$and $\left.\mathrm{SO}_{4 \mathrm{aq}}^{2-}, 2 \mathrm{H}_{\mathrm{aq}}^{+}\right)$, which could be transformed into $\mathrm{H}_{2 \mathrm{~g}}$ after $\gamma$-radiolysis as it was already described in the literature (Baumann, 1966; Swyler et al., 1983a). Small quantities of $\mathrm{CO}_{2 \mathrm{~g}}$ were measured, but its presence cannot be explained by the degradation of the $-\mathrm{SO}_{3} \mathrm{H}$ functional groups and the backbone, which is also very stable and which requires high doses to be oxidized. One hypothesis could be the possible oxidation of additives used in the industrial fabrication of AmbH resin. Experimentally, the presence of additives was confirmed by the measure 


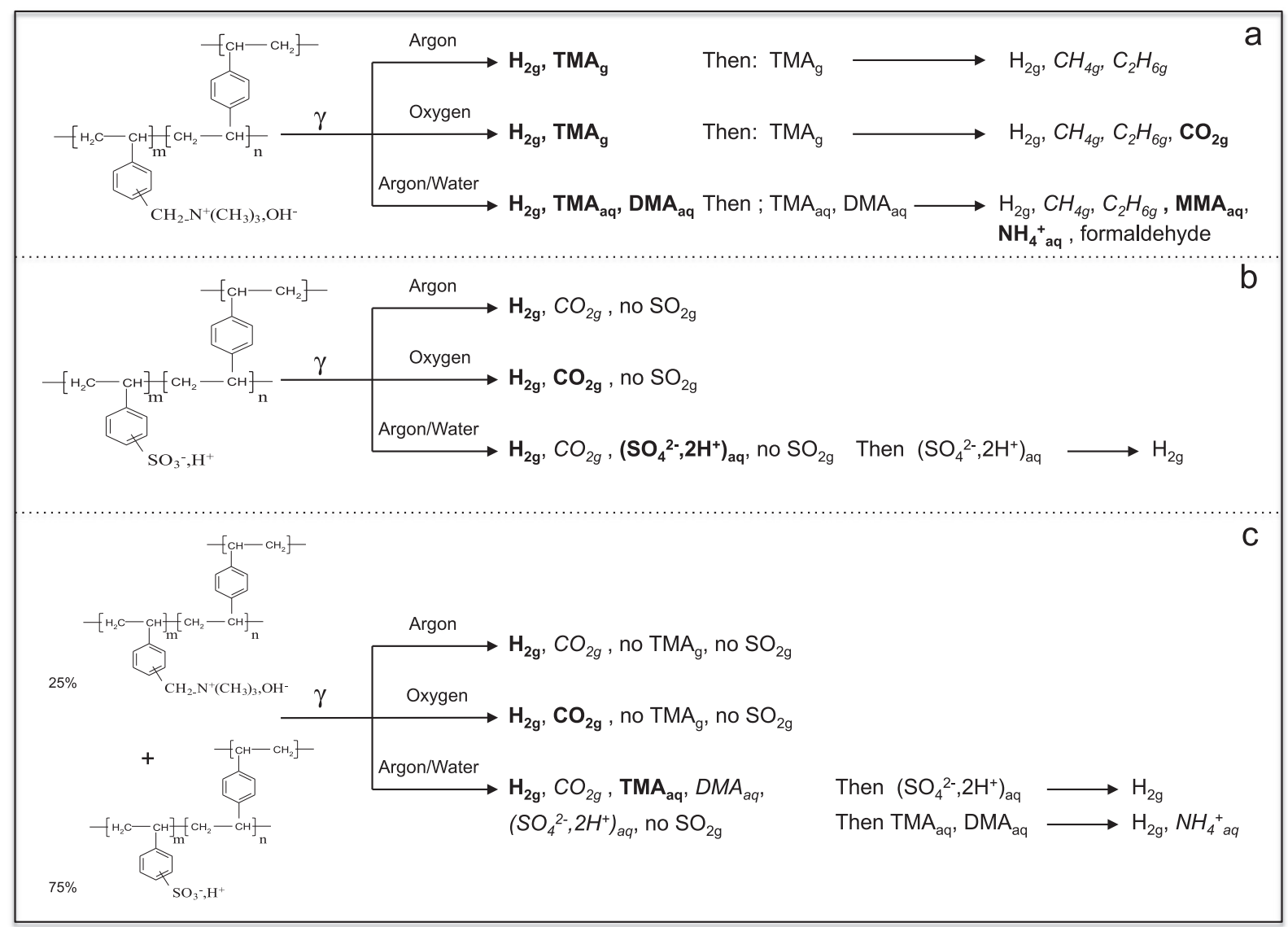

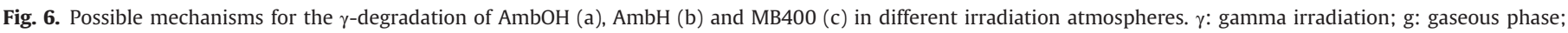
aq: aqueous phase; in bold: compound detected in quantitative amount; in italic: traces of compound.

of an important value of Total Organic Carbon after the leaching of no irradiated $\mathrm{AmbH}$ resin in ionized water.

The degradation of MB400 resin resulted in the formation of previously identified radiolysis products (Fig. 6c). Nevertheless aqueous amine and sulfate production occurred only at $3 \mathrm{MGy}$ and in small quantities. Additional experiments conduced at absorbed doses between 4 and 7 MGy (non presented in Table 5) showed that the concentration of sulfate and amines increased with the dose. A maximum for the radiolytic yields was reached for each compound at $5 \mathrm{MGy}$ and it was equal of $0.52,0.10,0.01$ and 0.05 for $G\left(\mathrm{SO}_{4 \mathrm{aq}}^{2-}\right), G\left(\mathrm{TMA}_{\mathrm{aq}}\right), G\left(\mathrm{DMA}_{\mathrm{aq}}\right)$ and $G\left(\mathrm{NH}_{4 \mathrm{aq}}^{+}\right)$, respectively). These results show that it was necessary to exceed a certain dose to degrade the MB400 resin. Moreover, the $\mathrm{pH}$ of the surnatant liquid after a gamma irradiation between 0.1 and $3 \mathrm{MGy}$ was between 6 and 7. In theses $\mathrm{pH}$ conditions, $\mathrm{TMA}_{\mathrm{aq}}$ formed after AmbOH degradation could become a trimethylammonium ion $\left(\mathrm{HN}^{+}\left(\mathrm{CH}_{3}\right)_{\mathrm{aq}}\right)$ which could be exchanged with $-\mathrm{SO}_{3} \mathrm{H}$ group of cation resin as described in the following equation:

$X-\mathrm{SO}_{3} \mathrm{H}+\mathrm{HN}^{+}\left(\mathrm{CH}_{3}\right)_{\mathrm{aq}} \rightarrow\left[\mathrm{X}-\mathrm{SO}_{3}\right]^{-},\left[\mathrm{HN}\left(\mathrm{CH}_{3}\right)_{3}\right]^{+}+\mathrm{H}_{\mathrm{aq}}^{+}$

To validate this hypothesis, an experiment was carried out in which $5 \mathrm{~g}$ of MB400 resin were swirled with standard solution of $\mathrm{TMA}_{\mathrm{aq}}$ $(25 \mathrm{mg} / \mathrm{L}), \operatorname{DMA}_{\mathrm{aq}}(5 \mathrm{mg} / \mathrm{L}), \mathrm{MMA}_{\mathrm{aq}}(5 \mathrm{mg} / \mathrm{L})$ and $\mathrm{NH}_{4 a q}^{+}(1 \mathrm{mg} / \mathrm{L})$. After three days, chromatographic analyses showed a decrease in the quantities of amines, which reached the detection limit of ion chromatography. The decrease in the amine content demonstrates that they are bound to $-\mathrm{SO}_{3} \mathrm{H}$ groups instead of the $\mathrm{H}^{+}$ions. This exchange was not observed by Middle Infrared analysis of the MB400 solid matrix because of the small proportion of $\mathrm{AmbOH}$ $(25 \% \mathrm{~W} / \mathrm{W})$. Only a few $-\mathrm{SO}_{3} \mathrm{H}$ functions were exchanged with $\mathrm{TMA}_{\mathrm{aq}}$ released in solution. This is the reason why most of the cation functional groups remained in their initial form (with $\mathrm{H}^{+}$) and did not lead to IR spectrum modifications. As for AmbOH and AmbH resins, molecular hydrogen was not produced by gamma radiolysis of the MB400 backbone because of its stability (Chang and LaVerne, 2000; Albano et al., 2003). Its formation was due to the degradation of interstitial and liquid water, the gamma radiolysis of the functional groups $\left(-\mathrm{N}^{+}\left(\mathrm{CH}_{3}\right)_{3},-\mathrm{SO}_{3} \mathrm{H}\right)$ and the radiation- induced degradation of radiolysis products (amines and sulfuric acid). In anaerobic atmosphere, the quantity of $\mathrm{H}_{2 \mathrm{~g}}$ after MB400 irradiation increased slowly and linearly with the absorbed dose. Its behavior was comparable in presence of oxygen between 0.1 and $3 \mathrm{MGy}$. With liquid water, the quantity of $\mathrm{H}_{2 \mathrm{~g}}$ was small between 0.1 and 3 MGy and increased rapidly above 4 MGy. This difference in behavior is probably due to the association between $\mathrm{SO}_{3}^{-}$groups of $\mathrm{AmbH}$ and $-\mathrm{N}^{+}\left(\mathrm{CH}_{3}\right)_{3}$ groups of $\mathrm{AmbOH}$ that make the most resistant mixed resin up to $3 \mathrm{MGy}$. When these functional groups are finally affected by radiolysis, they are released in the liquid water where they then undergo $\gamma$-degradation as described above to form $\mathrm{TMA}_{\mathrm{aq}}$ and $\mathrm{SO}_{4 \mathrm{aq}}^{2-}$. Additional experiments done outside the experimental design showed that $4 \mathrm{MGy}$ was a cutoff dose above which water-soluble products (amines and sulfuric acid) were released and degraded, generating $\mathrm{H}_{2 \mathrm{~g}}$. Under an absorbed dose of 4,5 or $7 \mathrm{MGy}$, the production yield of $\mathrm{TMA}_{\mathrm{aq}}$ and $\mathrm{SO}_{4 \mathrm{aq}}^{2-}$ species was $0.03-0.07 \%$ and $0.31-0.39 \%$, respectively. Very low yields were obtained for $\mathrm{DMA}_{\mathrm{aq}}$ and $\mathrm{NH}_{4 \mathrm{aq}}^{+}$forms (nearly $0.01 \%$ and $0.04 \%$, respectively). In presence of oxygen, this gas was consumed as with $\mathrm{AmbOH}$ and $\mathrm{AmbH}$ taken separately, and one fraction was converted to carbon dioxide in quantities comparable to those observed after AmbOH irradiation $(0.8 \mathrm{~mol} / \mathrm{kg}$ of resin). The explanations for the formation of this gas were discussed above. Swyler et al. (1983a) also measured $\mathrm{CO}_{2 \mathrm{~g}}$ release. 


\section{Conclusion}

A chemometric strategy based on combining an experimental design approach and response methodology was applied to gain further knowledge on the influence of gamma irradiation factors (absorbed dose, irradiation atmosphere, dose rate) on the ageing process of ion exchange resins. The results obtained indicated that these materials reacted differently by applying different combinations of factor conditions. The main products of $\gamma$-radiolysis of the three resins were molecular hydrogen, carbon dioxide, and trimethylamine in gaseous phase. Significant quantities of gaseous carbon dioxide were found only when resins were irradiated in presence of oxygen. TMA $\mathrm{g}$ was only produced by $\gamma$-degradation of AmbOH. No traces of gaseous sulfur dioxide and nitrogen oxide were detected. In presence of liquid water, water-soluble products were detected including trimethylamine, dimethylamine, monomethylamine, ammonia (only after irradiation of $\mathrm{AmbOH}$ and MB400), sulfate ions (after radiolysis of AmbH and MB400) and formaldehyde (only in the case of AmbOH). The significant factor governing the hydrogen production after gamma radiolysis degradation of the studied resins was the absorbed dose above $1 \mathrm{MGy}$. The presence of oxygen decreased $\mathrm{H}_{2 \mathrm{~g}}$ production from $\mathrm{AmbOH}$ and MB400 because of the oxidation of trimethylammonium groups instead. Only the cation resin appeared to exhibit different behavior in anaerobic atmosphere with liquid water because its degradation involved the formation of sulfuric acid whose the $\gamma$-radiolysis contributed to the $\mathrm{H}_{2 \mathrm{~g}}$ production. In the mixed bed, the ammonium quaternary groups of the anion resin appeared more resistant to gamma radiolysis because the free $\mathrm{H}_{2}$ quantity was smaller in presence of the cation sample, in the same proportions. The comparison of the three resins behavior showed that the mixed bed ion exchange resin was globally more stable than its individual components in terms of hydrogen and amine production.

\section{Acknowledgments}

We are thankful to AREVA for giving us the opportunity to investigate the effect of gamma radiation on the degradation of ion exchange resins and for its financial support.

\section{References}

Addelman, S., 1962. Orthogonal main-effect plans for asymmetrical factorial experiments. Technometrics 4, 489-495.

Ahmed, M.T., Clay, P.G., Hall, G.R., 1966. Radiation-induced decomposition of ionexchange resins: Part II. The mechanism of the deamination of anion-exchange resins. J. Chem. Soc. B, 1155-1157.

Albano, C., Reyes, J., Ichazo, M., González, J., Hernández, M., Rodríguez, M., 2003. Mechanical, thermal and morphological behaviour of the polystyrene/polypropylene (80/20) blend, irradiated with $\gamma$-rays at low doses (0-70 kGy). Polym. Degrad. Stab. 80, 251-261.

Alian, A., Dessouki, A., El-Bassy, N.B., 1984. Ion exchange resins as high-dose radiation dosimeters. Radiat. Phys. Chem. 23, 441-444.

Baidak, A., LaVerne, J.A., 2010. Radiation-induced decomposition of anion exchange resins. J. Nucl. Mater. 407, 211-219.

Basinski, A., Narabeska, A., Tempczyk, M., 1969. Effect of gamma radiation on ion exchange resins. I-Irradiation damage of functional groups in the strong base anion exchange resin Zerlit FF-IP. Nukleonika 14, 509-519.

Baumann, E.W., 1966. Gamma irradiation of individual and mixed ion exchange resins. J. Chem. Eng. Data 11, 256-260.

Cau-dit-coumes, C., 1999. Cimentation de résines échangeuses d'ions irradiées: éléments de bibliographie. Rapport NTSEP 99/747, CEA.

Chang, Z., LaVerne, J.A., 2000. Hydrogen production in $\gamma$-ray and helium-ion radiolysis of polyethylene, polypropylene, poly(methyl-methacrylate), and polystyrene. J. Polym. Sci., Part A: Polym. Chem. 38, 1656-1661.
Dannoux, A., 2007. Extrapolation dans le temps des cinétiques de production des produits de dégradation radiolytique, Application à un polyuréthane, Saclay, Paris XI.

Dely, N., Esnouf, S., Legand, S., Dauvois, V., Dannoux, A., Amekraz, B., Moulin, C., 2008. Radiolyse $\gamma$ des polymères: production de gaz en conditions inertes, Rapport CEA-NT DPC/SECR 08-017 indice A.

Dessouki, A.M., Zahran, A.H., Rabie, A.M., Amer, S.I., 1989. Some investigations on the radiation stability of a strongly acidic cation exchange resin. Radiat. Phys. Chem. 33, 545-549.

Dhiman, S.B., LaVerne, J.A., 2013. Radiolysis of simple quaternary ammonium salt components of Amberlite resin. J. Nucl. Mater. 436, 8-13.

Farah, K., Jerbi, T., Kuntz, F., Kovács, A., 2006. Dose measurements for characterization of a semi-industrial cobalt-60 gamma-irradiation facility. Radiat. Meas. 41, 201-208.

Fedorov, V.V., Malyutov, M.B., 1972. Optimal design in regression experiments Math. Operationsforsch. Stat. 14, 237-324.

Felines, I., Toncelli, C., Camaro, S., 1995. Irradiation de résines échangeuses d'ions dans le cadre de la reprise des déchêts du Silo HAO. Rapport SEP-95/419, CEA.

Gangwer, T.E., Goldstein, M., Pillay, K.K.S., 1977. Radiation effects on ion exchange materials (Rep. BNL). Departement of Energy and Environnement.

Garett, B.C., Dixon, D.A., Camaioni, D.M., Chipman, D.M., Johnson, M.A., Jonah, C.D., 2005. Role of water electron-initiated processes and radical chemistry: issues and scientific advances. Chem. Rev. 105, 355-389.

Hall, G.R., Streat, M., 1963. Radiation-induced decomposition of ion-exchange resins: Part I. Anion-exchange resins. J. Chem. Soc. 37, 5205-5211.

Ichikawa, T., Hagiwara, Z., 1973. Effect of gamma-irradiation on a cation exchange resin. J. Nucl. Sci. Technol. 10, 746-752.

Kiseleva, E.D., Chmutov, K.V., Kuligina, N.V., 1970. The mechanism of the effect of ionising radiation on AV-17 anion-exchange resin. Zh. Fiz. Khim. 44, 236-261.

Leardi, R., 2009. Experimental design in chemistry: a tutorial. Anal. Chim. Acta 652 $161-172$.

Le Caër, S., Rotureau, P., Brunet, F., Charpentier, T., Blain, G., Renault, J.P., Mialocq J.C., 2005. Radiolysis of confined water: hydrogen production at high dose rate. ChemPhysChem 6, 2585-2596.

Lesigne, B., Ferradini, C., Pucheault, J., 1973. Pulse radiolysis study of the direct effect on sulfuric acid. J. Phys. Chem. 77, 2156-2158.

Lind, S.C., 1961. Radiation Chemistry of Gases. Reinhold Publishing Corporation, New York.

Litowska, M., Narebska, A., Ostrowska, J., 1974. Effect of gamma radiation on ion exchange resins. VI. The kinetics and mechanisms of radiation-induced decomposition of functional groups in an IMAC S5-40 anion exchange resin. Nukleonika 19, 19-29.

Lundstedt, T., Seifert, E., Abramo, L., Thelin, B., Nyström, A., Pettersen, J., Bergman, R., 1998. Experimental design and optimization. Chemom. Intell. Lab 42, 3-40.

Mathieu, D., Nony, J., Phan-Tan-Luu, R., 2000. NemrodW, Version 2000, LPRAI, Marseille, 〈http://www.nemrodw.com $\rangle$.

Myers, D.C., Schmidt-Bleek, F., 1967. Low-conversion radiolysis of méthane containing traces of oxygen and olefins. J. Phys. Chem. 72, 1475-1482.

Mohorčič, G., Kramer, V., Pregel, J., 1974. Interaction of a sulfonic acid ion exchange resin with tritiated water on $\gamma$-irradiation. Int. J. Appl. Radiat. Isot. 25, 177-182.

Narebska, A., Basinski, A., Litowska, M., 1970. Effect of gamma radiation on ion exchange resins. II-Investigation of the effect of gamma radiation on Zero lit FF-IP by the IR method. Nukleonika 15, 30-39.

Nikashina, V.A., Breger, A.Kh., Senyavin, M.M., 1959. Stability of the cation exchange resins. Int. J. Appl. Radiat. Isot. 4, 201-209.

Pillay, K.K.S., 1986. A review of the radiation stability of ion exchange materials J. Radioanal. Nucl, 247-268 (Ch. 102).

Sami, M.A., Smithies, D., 1974. Primary yields in the $\gamma$-radiolysis of gazeous aliphatic amines. J. Chem. Soc., Faraday Trans. 70, 51-57.

Semushin, A.M., Shistyakov, D.A., Kuzin, I.A., 1950. Investigation of the influence of oxygen on the radiolysis of the sulfonic acid cation-exchanger KU-2-8. J. Appl. Chem. URSS 52, 268-271.

Swyler, K.J., Dodge, C.J., Dayal, R., 1983a. Irradiation Effects on the Storage and Disposal of Radwaste Containing Organic Ion-Exchange Media. United States Nuclear Regulatory Commission.

Swyler, K.J., Dodge, C.E., Dayal, R., Weiss, A.J., 1983b. Irradiation Effects on the Storage and Disposal of Radioactive ion-Exchange Resins (Report BNL-NUREG31 894). United States Nuclear Regulatory Commission.

Takamuku, S., Sakurai, H., 1965. The radiolysis of mono, di- and trimethylamine in the gas phase. Bull. Chem. Soc. Jpn. 38, 791-794.

Traboulsi, A., Dupuy, N., Rebufa, C., Sergent, M., Labed, V., 2012. Investigation of gamma radiation effect on the anion exchange resin Amberlite IRA-400 in hydroxide form by Fourier transformed infrared and ${ }^{13} \mathrm{C}$ nuclear magnetic resonance spectroscopies. Anal. Chim. Acta 717, 110-121.

Yamada, R., Nagaishi, R., Hatano, Y., Yoshida, Z., 2008. Hydrogen production in the $\gamma$-radiolysis of aqueous sulfuric acid solutions containing $\mathrm{Al}_{2} \mathrm{O}_{3}, \mathrm{SiO}_{2}, \mathrm{TiO}_{2}$ or $\mathrm{ZrO}_{2}$ fine particles. Int. J. Hydrogen Energy 33, 929-936.

Yamada, R., Kumagai, Y., Nagaishi, R., 2011. Effect of alumina on the enhancement of hydrogen production and the reduction of hydrogen peroxide in the $\gamma$-radiolysis of pure water and $0.4 \mathrm{M} \mathrm{H}_{2} \mathrm{SO}_{4}$ aqueous solution. Int. J. Hydrogen Energy 36, 646-1153. 